\title{
Discovery of Phthalazinone Derivatives as Novel Hepatitis B Virus Capsid Inhibitors
}

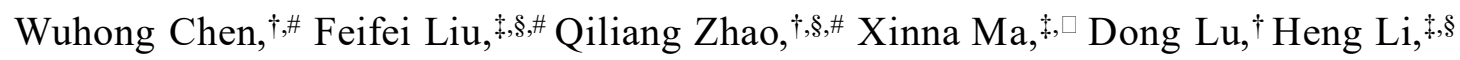

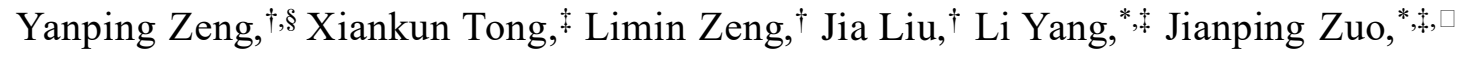
and Youhong $\mathrm{Hu}^{*}, \dagger, \S, \|$

$\dagger$ State Key Laboratory of Drug Research, Shanghai Institute of Materia Medica, Chinese Academy of Sciences, 555 ZuChongZhi Road, Shanghai, 201203, China

$\$$ Laboratory of Immunopharmacology, Shanghai Institute of Materia Medica, Chinese Academy of Sciences, 555 ZuChongZhi Road, Shanghai, 201203, China

$\S$ University of Chinese Academy of Sciences, No. 19A Yuquan Road, Beijing, 100049, China

Laboratory of Immunology and Virology, Shanghai University of Traditional Chinese Medicine, Shanghai, 201203, China.

"School of Pharmaceutical Science and Technology, Hangzhou Institute for Advanced Study, UCAS, Hangzhou 310024, China.

\section{Supporting information}

\section{Content}

Figure S1. Tissue distributions and plasma concentration-time curves of $\mathbf{4 r}$ in SD rats and mice

Table S1. Single-dose pharmacokinetics of $4 \mathrm{r}$ in mice S3

Table S2. Metabolism of S4a in HLM with GSH S3

Figure S2. Metabolic pathway of S4a in HLM with GSH S4

Figure S3. Tissue distributions and plasma concentration-time curves of $\mathbf{1 0 m}$ 
Figure S4. Tissue distributions and plasma concentration-time curves of $\mathbf{1 9 f}$

Table S3. SAR study of the substituents on the 2-position of pyridazinone

Figure S5. Levels of HBV DNA in the plasma of AAV/HBV-infected mice by treatment of $\mathbf{1 9 f}$ with $100 \mathrm{mg} / \mathrm{kg}$, bid

Detailed experimental procedures for the synthesis of analogues $10 \mathbf{a}, \mathbf{1 0 b}, \mathbf{1 0 i}, \mathbf{1 0 j}, \mathbf{1 0 k}$ and intermediates 18h-18n

Characterization of the selected final compounds $10 \mathrm{l}, 10 \mathrm{~m}, 18 \mathrm{a}, 18 \mathrm{~b}, 18 \mathrm{~d}, 18 \mathrm{e}, 18 \mathrm{~g}$,

19a, 19b, 19c, 19d, 19e, 19f, 19g, 19h $\left({ }^{1} \mathrm{HNMR}\right.$ spectra ${ }^{13} \mathrm{CNMR}$ spectra were attached)

HPLC purity control of selected final compounds

Reference 

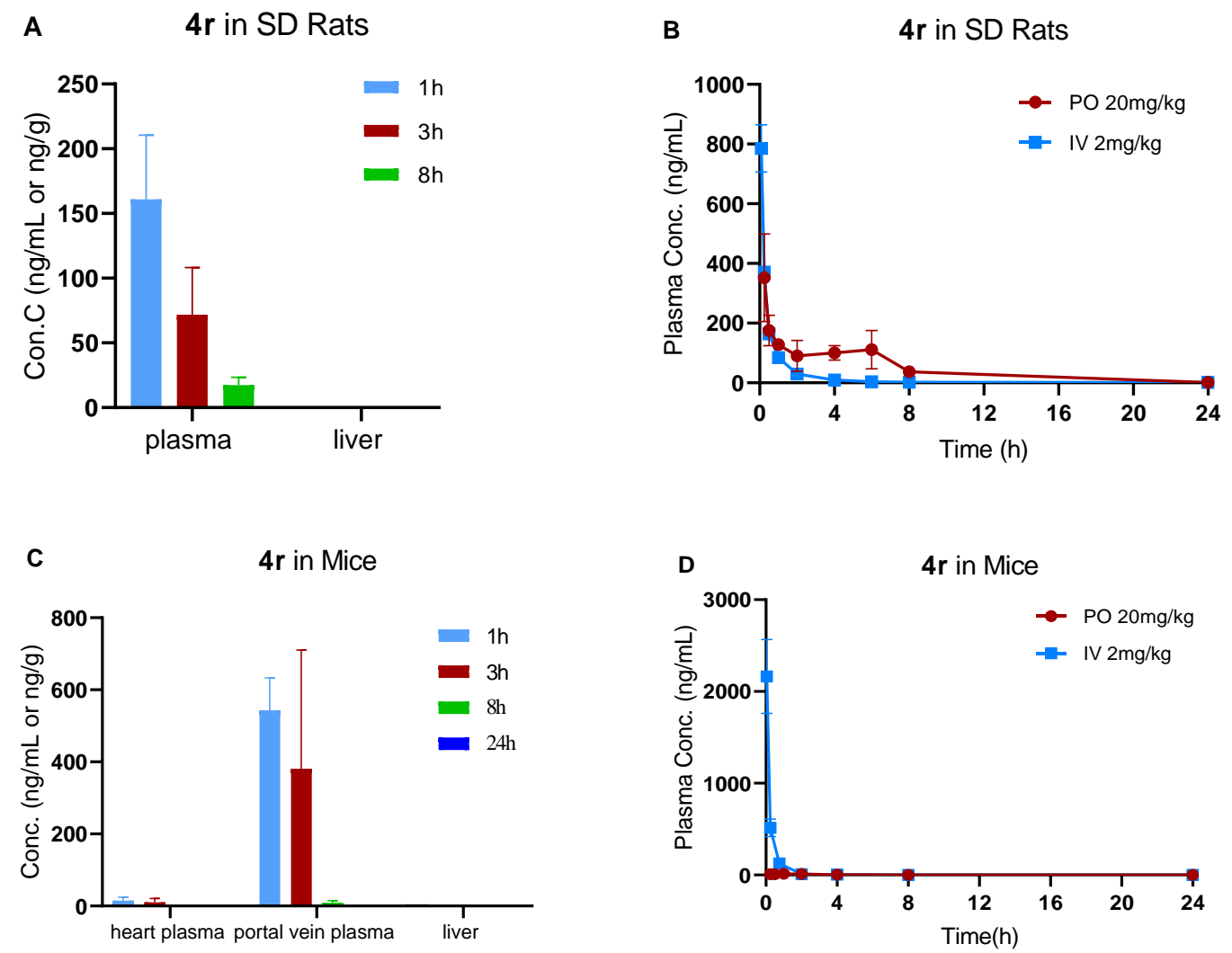

Figure S1. Tissue distribution profiles of $\mathbf{4 r}$ in SD rats $(\mathbf{A})$ and mice $(\mathbf{C})$ at different time points after a single oral administration of $20 \mathrm{mg} / \mathrm{kg}($ mean $\pm \mathrm{SD}, \mathrm{n}=3$ ). Mean plasma concentration-time curves for $4 \mathbf{r}$ after administration of $20 \mathrm{mg} / \mathrm{kg}$ orally and 2 $\mathrm{mg} / \mathrm{kg}$ intravenously to SD rats (B) and mice (D).

Table S1. Single-Dose Pharmacokinetics of $4 \mathbf{r}$ in Mice $^{\mathrm{a}}$

\begin{tabular}{|c|c|c|c|c|c|c|c|c|}
\hline $\begin{array}{c}\text { Dose } \\
(\mathrm{mg} / \mathrm{kg})\end{array}$ & $\begin{array}{l}\mathbf{T}_{1 / 2} \\
\text { (h) }\end{array}$ & $\begin{array}{l}\mathbf{T}_{\max } \\
\text { (h) }\end{array}$ & $\begin{array}{c}\mathbf{C}_{\max } \\
(\mathrm{ng} / \mathrm{mL})\end{array}$ & $\begin{array}{c}\mathbf{A} \mathbf{U} \mathbf{C}_{\mathbf{0 - t}} \\
(\mathrm{h} * \mathrm{ng} / \mathrm{mL})\end{array}$ & $\begin{array}{l}\text { AUC } \mathbf{C I N F}_{\mathbf{I N} \mathbf{o b s}} \\
\left(\mathrm{h}^{*} \mathrm{ng} / \mathrm{mL}\right)\end{array}$ & $\begin{array}{c}\text { CL_obs } \\
(\mathrm{mL} / \mathrm{min} / \mathrm{kg})\end{array}$ & $\begin{array}{c}\text { Vss_obs }_{-} \\
(\mathrm{mL} / \mathrm{kg})\end{array}$ & $\begin{array}{c}\mathbf{F} \\
(\%)\end{array}$ \\
\hline po(20) & $1.52 \pm 0.15$ & $1.33 \pm 0.58$ & $13.1 \pm 3.9$ & $41.7 \pm 13.6$ & $43.3 \pm 14.4$ & - & - & 0.73 \\
\hline $\operatorname{iv}(2)$ & $1.04 \pm 0.45$ & - & - & $568 \pm 66$ & $569 \pm 66$ & $59.1 \pm 6.6$ & $1371 \pm 443$ & \\
\hline
\end{tabular}

Table S2. Metabolism of S4a in HLM with GSH

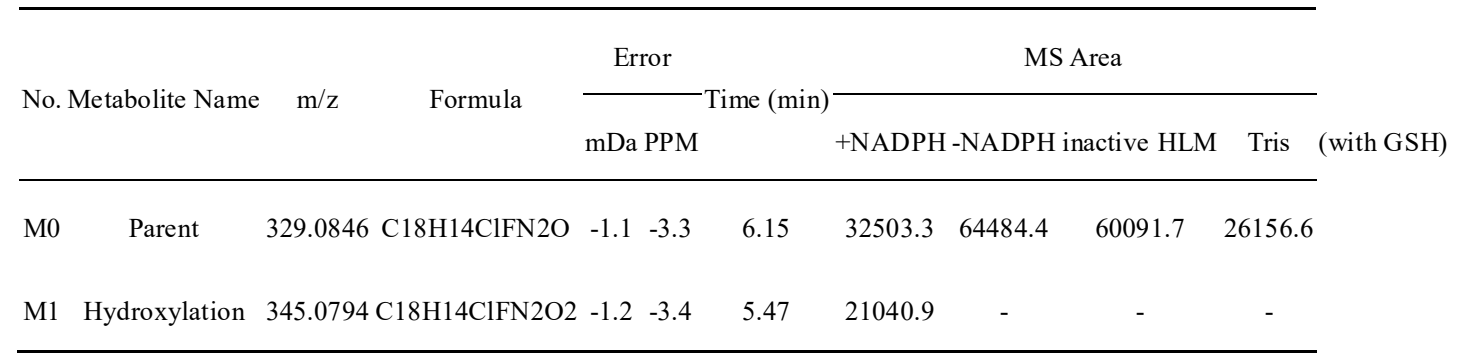


<smiles>Cc1cc(-c2ccc(F)cc2)nn(Cc2ccc(Cl)cc2)c1=O</smiles>

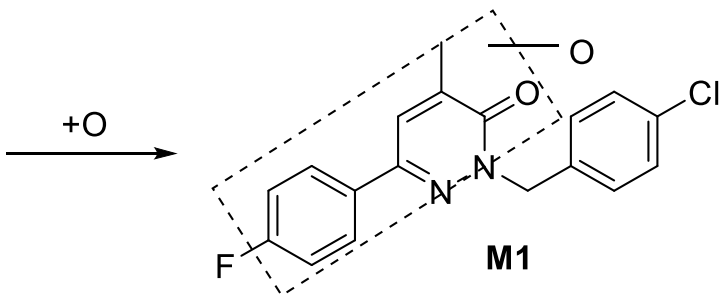

Figure S2. Metabolic pathway of S4a in HLM with GSH.
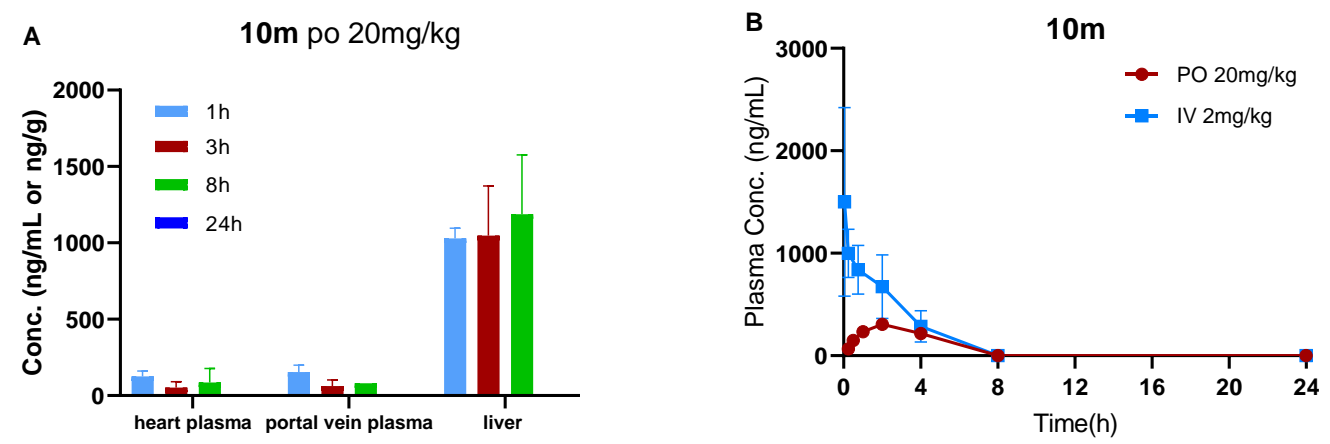

Figure S3. (A) Tissue distribution profiles of $\mathbf{1 0 m}$ in mice at different time points after a single oral administration of $20 \mathrm{mg} / \mathrm{kg}$ (mean $\pm \mathrm{SD}, \mathrm{n}=3$ ). (B) Mean plasma concentration-time curves for $\mathbf{1 0 m}$ after administration of $20 \mathrm{mg} / \mathrm{kg}$ orally and $2 \mathrm{mg} / \mathrm{kg}$ intravenously to mice.

A

$19 f \mathrm{po} 20 \mathrm{mg} / \mathrm{kg}$

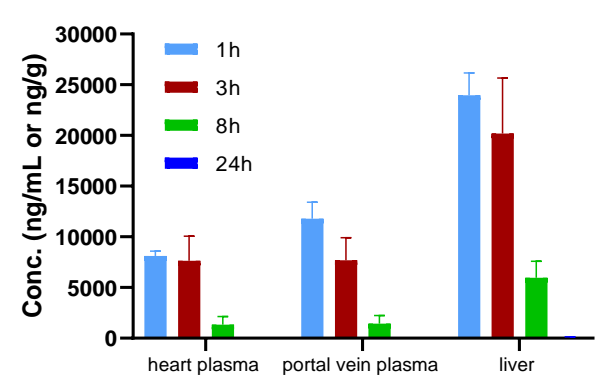

B $19 f$

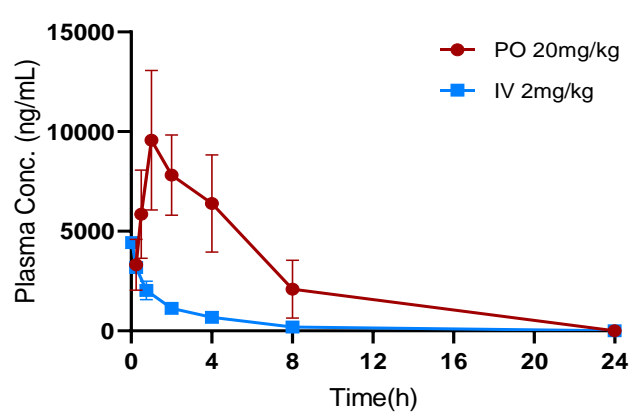

Figure S4. (A) Tissue distribution profiles of 19f in mice at different time points after a single oral administration of $20 \mathrm{mg} / \mathrm{kg}$ (mean $\pm \mathrm{SD}, \mathrm{n}=3$ ). (B) Mean plasma concentration-time curves for $\mathbf{1 9 f}$ after administration of $20 \mathrm{mg} / \mathrm{kg}$ orally and $2 \mathrm{mg} / \mathrm{kg}$ intravenously to mice. 
Table S3. SAR study of the substituents on the 2-position of pyridazinone

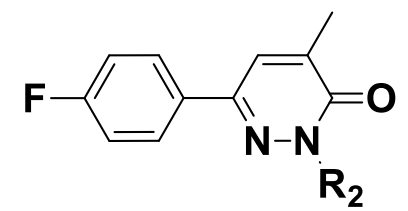

Compd.

${ }^{\mathrm{a}} \mathrm{IC}_{50}$ is $50 \%$ inhibitory concentration of cytoplasmic HBV-DNA replication. ${ }^{\mathrm{b}} \mathrm{CC}_{50}$ is $50 \%$ cytotoxicity concentration in HepG2 2.2.15 cells. ${ }^{c}$ Selectivity index ( $\mathrm{SI}=\mathrm{CC}_{50} /$ $\left.\mathrm{IC}_{50}\right) .{ }^{\mathrm{d}} \mathrm{NA}=$ not active at concentration of $\mathrm{CC}_{50}$. 
Levels of HBV DNA in the plasma of AAV/HBV-infected mice by treatment of $\mathbf{1 9 f}$ with $100 \mathrm{mg} / \mathrm{kg}$, bid

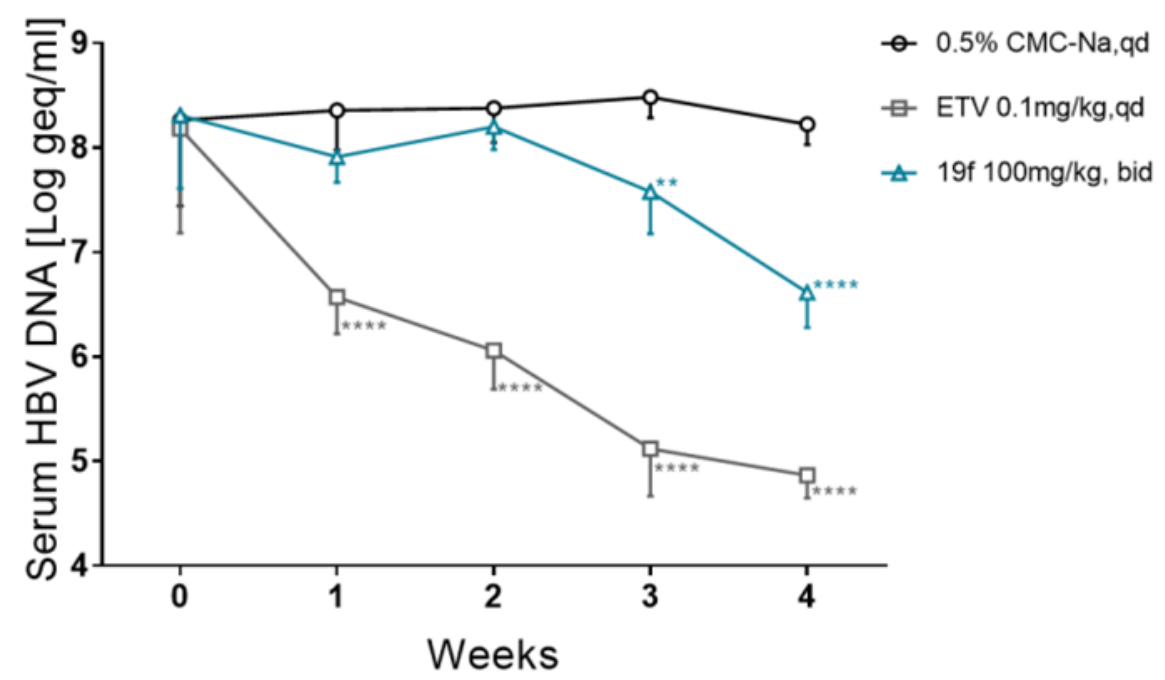

Figure S5. Levels of HBV DNA in the Plasma of AAV/HBV-Infected Mice by Treatment of $\mathbf{1 9 f}$ with $100 \mathrm{mg} / \mathrm{kg}$, bid.

$19 f$ was dosed orally twice a day for 4 weeks at a dose of $100 \mathrm{mg} / \mathrm{kg}$, whereas $0.5 \%$ CMC-Na and $0.1 \mathrm{mg} / \mathrm{kg}$ ETV was dosed once a day orally and served as negative and positive control, respectively. In comparison to the model control group $(0.5 \% \mathrm{CMC}$ $\mathrm{Na}$ ), treatment with $100 \mathrm{mg} / \mathrm{kg}$ of $\mathbf{1 9 f}$ achieved $1.69 \mathrm{log}$ viral load reduction on week4 (Dunnett's multiple comparisons test, $\mathrm{P}<0.0001$ ). Data are shown as the mean $\pm \mathrm{SD}$. The number of animals per group for data analysis was 5 . 
Detailed experimental procedures for the synthesis of analogues $10 \mathrm{a}, \mathbf{1 0 b}, \mathbf{1 0 i}, \mathbf{1 0 j}, \mathbf{1 0 k}$ and intermediates 18h-18n

\section{1. synthesis of analogues $10 \mathrm{a}-10 \mathrm{~b}$}
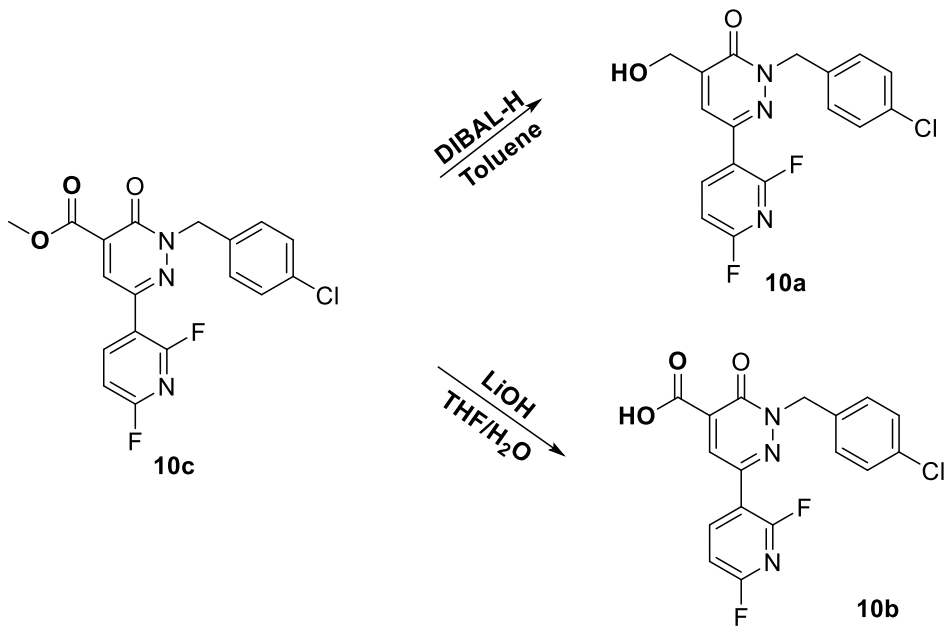

To a solution of $10 \mathrm{c}(100 \mathrm{mg}, 0.26 \mathrm{mmol})$ in toluene $(5 \mathrm{~mL})$ at $-10{ }^{\circ} \mathrm{C}$ was added DIBAL-H (0.52 mL, 1M in Cyclohexane, $0.52 \mathrm{mmol}, 2.0$ equiv) under nitrogen. After the reaction was stirred for $30 \mathrm{~min}$, a saturated solution of potassium sodium tartrate ( 5 $\mathrm{mL}$ ) was added and the mixture was extracted with ethyl acetate. The combined organic layers were dried, filtrated and concentrated. Purification of the crude product by column chromatography on silica gel $($ Hexane/EtOAc $=2 / 1, \mathrm{v} / \mathrm{v})$ gave $\mathbf{1 0 a}$.

A mixture of 10c (100 mg, $0.25 \mathrm{mmol})$ and $\mathrm{LiOH}(12.2 \mathrm{mg}, 0.51 \mathrm{mmol}, 2.0$ equiv) in THF $(5 \mathrm{~mL})$ and water $(1 \mathrm{~mL})$ was stirred at r.t. for $0.5 \mathrm{~h}$. Then, the mixture was acidified with concentrated aqueous $\mathrm{HCl}$ until a white solid precipitates. The solid was collected by filtration and washed with water $(5 \mathrm{~mL})$ to give the product $\mathbf{1 0 b}$.

\section{2. synthesis of analogue $10 \mathrm{i}$}

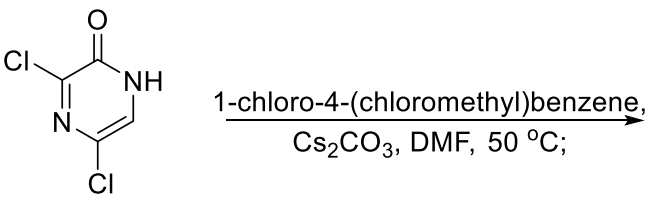

11

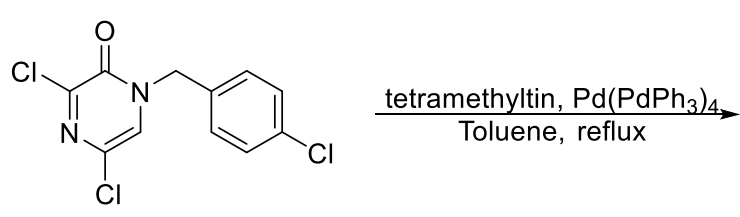

12<smiles>Cc1nc(Cl)cn(Cc2ccc(Cl)cc2)c1=O</smiles>

13

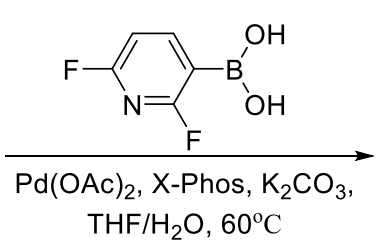

$\mathrm{THF} / \mathrm{H}_{2} \mathrm{O}, 60^{\circ} \mathrm{C}$<smiles>Cc1nc(-c2ccc(F)nc2F)cn(Cc2ccc(Cl)cc2)c1=O</smiles> 
To a solution of 3,5-dichloropyrazin-2(1H)-one 11 (1.0 g, $6.1 \mathrm{mmol})$ in DMF (30 $\mathrm{mL})$ was added $\mathrm{Cs}_{2} \mathrm{CO}_{3}(2.2 \mathrm{~g}, \quad 6.7 \mathrm{mmol}, 1.1$ equiv) and 1-chloro-4(chloromethyl)benzene (1.1 g, $6.7 \mathrm{mmol}, 1.1$ equiv). The resulting mixture was stirred at $50{ }^{\circ} \mathrm{C}$ for $7 \mathrm{~h}$, then the solvent was removed under reduced pressure. The residue was diluted with water $(100 \mathrm{~mL})$ and extracted with ethyl acetate $(50 \mathrm{~mL} \times 3)$ and the combined organic layers were washed with brine $(100 \mathrm{~mL})$, dried over anhydrous $\mathrm{Na}_{2} \mathrm{SO}_{4}$, filtered and concentrated to give the crude product, which was further purified by column chromatography on silica gel eluting with $25 \%$ ethyl acetate in hexane to give the desired product chromatography to afford compound $\mathbf{1 2}(1.27 \mathrm{~g}, 72 \%)$.

A mixture of compound $12(0.50 \mathrm{~g}, 1.73 \mathrm{mmol})$, tetramethyltin $(0.371 \mathrm{~g}, 2.1 \mathrm{mmol}$, 1.2 equiv) and $\mathrm{Pd}\left(\mathrm{PPh}_{3}\right)_{4}(20 \mathrm{mg}, 0.017 \mathrm{~mol}, 0.01$ equiv $)$ in toluene $(10 \mathrm{~mL})$ was heated at $110{ }^{\circ} \mathrm{C}$ for 24 h. ${ }^{1}$ Upon completion of the reaction and removal of the solvent under vacuum, the residue was dissolved in EtOAc and stirred with an excess KF for $4 \mathrm{~h}$ at room temperature. After filtration of the mixture, the filtrate was evaporated and purified by column chromatography (silica gel, $10 \% \mathrm{EtOAc} / \mathrm{CH}_{2} \mathrm{Cl}_{2}$, v/v) to afford 13 (0.38 g, $81 \%$ ); ${ }^{1} \mathrm{H}$ NMR (400 MHz, Chloroform-d) $\delta 8.07$ (s, 1H), $7.42-7.34$ (m, 4H), $5.23(\mathrm{~s}, 2 \mathrm{H}), 2.41(\mathrm{~s}, 3 \mathrm{H})$.

To a three-necked round bottom flask was added $13(100 \mathrm{mg}, 0.37 \mathrm{mmol})$, $\mathrm{Pd}(\mathrm{OAc})_{2}(4.17 \mathrm{mg}, 0.018 \mathrm{mmol}, 0.05$ equiv), X-Phos (17.71 mg, $0.037 \mathrm{mmol}, 0.1$ equiv), potassium carbonate (102mg, $0.54 \mathrm{mmol}, 2.0$ equiv) under the atmosphere of nitrogen, followed by adding the combined solution of tetrahydrofuran $(8 \mathrm{~mL})$ and water $(2 \mathrm{~mL})$. Then a solution of (2,6-difluoropyridin-3-yl)boronic acid (70 mg, 0.48 mmol, 1.2 equiv) in THF ( $2 \mathrm{~mL})$ was added dropwise. The resulting mixture was stirred at $60{ }^{\circ} \mathrm{C}$ for $2 \mathrm{~h}$, after cooling, the reaction mixture was filtered and the filtrate was extracted with ethyl acetate $(15 \mathrm{~mL} \times 3)$ and the combined organic layers were washed with brine $(10 \mathrm{~mL})$, dried over anhydrous $\mathrm{Na}_{2} \mathrm{SO}_{4}$, filtered and concentrated to give the crude product, which was further purified by column chromatography to afford compounds 10i as powder. 


\section{3. synthesis of analogue $10 \mathrm{j}$}

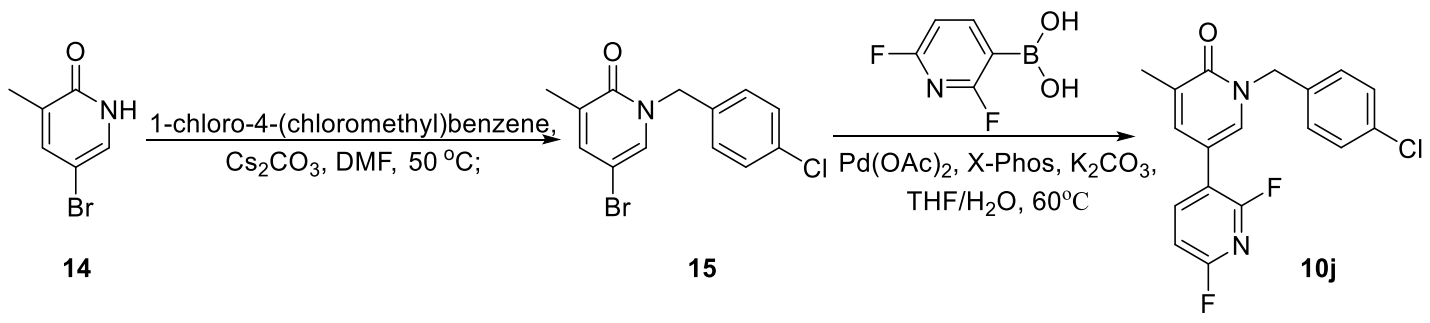

To a solution of 5-bromo-3-methylpyridin-2(1H)-one $14(1.0 \mathrm{~g}, 5.3 \mathrm{mmol})$ in DMF $(50 \mathrm{~mL})$ was added $\mathrm{Cs}_{2} \mathrm{CO}_{3}(1.9 \mathrm{~g}, 5.8 \mathrm{mmol}, 1.1$ equiv) and 1-chloro-4(chloromethyl)benzene ( $0.95 \mathrm{~g}, 5.8 \mathrm{mmol}, 1.1$ equiv). The resulting mixture was stirred at $50{ }^{\circ} \mathrm{C}$ for $7 \mathrm{~h}$, then the solvent was removed under reduced pressure. The residue was diluted with water $(50 \mathrm{~mL})$ and extracted with ethyl acetate $(30 \mathrm{~mL} \times 3)$ and the combined organic layers were washed with brine $(50 \mathrm{~mL})$, dried over anhydrous $\mathrm{Na}_{2} \mathrm{SO}_{4}$, filtered and concentrated to give the crude product, which was further purified by column chromatography on silica gel eluting with $25 \%$ ethyl acetate in hexane to afford compound $15(1.1 \mathrm{~g}, 66 \%)$.

To a three-necked round bottom flask was added 15 (100 mg, 0.32mmol ), $\mathrm{Pd}(\mathrm{OAc}) 2$ (3.59mg, 0.016mmol, 0.05 equiv), X-Phos (15.2mg, 0.032mmol, 0.1 equiv), potassium carbonate ( $88 \mathrm{mg}, 0.64 \mathrm{mmol}, 2.0$ equiv) under the atmosphere of nitrogen, followed by adding the combined solution of tetrahydrofuran $(8 \mathrm{~mL})$ and water $(2 \mathrm{~mL})$. Then a solution of (2,6-difluoropyridin-3-yl)boronic acid (61 mg, $0.38 \mathrm{mmol}, 1.2$ equiv) in THF ( $2 \mathrm{~mL}$ ) was added dropwise. The resulting mixture was stirred at $60{ }^{\circ} \mathrm{C}$ for $2 \mathrm{~h}$, after cooling, the reaction mixture was filtered and the filtrate was extracted with ethyl acetate $(15 \mathrm{~mL} \times 3)$ and the combined organic layers were washed with brine $(10$ $\mathrm{mL}$ ), dried over anhydrous $\mathrm{Na}_{2} \mathrm{SO}_{4}$, filtered and concentrated to give the crude product, which was further purified by column chromatography with $20 \%$ ethyl acetate in hexane to afford compound $\mathbf{1 0} \mathbf{j}$ as powder.

\section{4. synthesis of analogue $10 \mathrm{k}$}

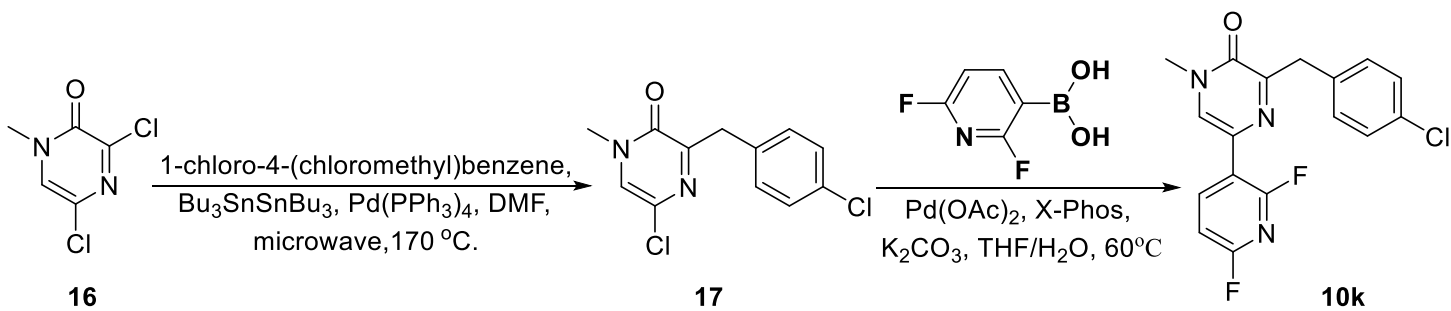


A mixture of 3,5-dichloro-1-methylpyrazin-2(1H)-one $\mathbf{1 6}(1 \mathrm{~g}, 5.6 \mathrm{mmol}), 1$ chloro-4-(chloromethyl)benzene (992 mg, $6.2 \mathrm{mmol}, 1.1$ equiv), hexabutyldistannane ( $3.6 \mathrm{~g}, 6.2 \mathrm{mmol}, 1.1$ equiv) and $\mathrm{Pd}\left(\mathrm{PPh}_{3}\right)_{4}(65 \mathrm{mg}, 0.056 \mathrm{mmol}, 0.01$ equiv) in $\mathrm{DMF}$ $(10 \mathrm{~mL})$ was irradiated in the cavity of a Milestone-MYCROSYNTH multimode oven at a preselected maximum temperature of $170{ }^{\circ} \mathrm{C}$ for $10 \mathrm{~min}$, using a maximum irradiation power of $120 \mathrm{~W}^{2}$ The mixture was then cooled to room temperature, poured into crushed ice and extracted with ethyl acetate $(20 \mathrm{~mL} \times 3)$. The combined organic layer was washed by saturated sodium chloride solution $(20 \mathrm{~mL} \times 3)$, dried over anhydrous $\mathrm{Na}_{2} \mathrm{SO}_{4}$ and concentrated under reduced pressure. The residue was purified by silica gel chromatography eluting with $30 \%$ ethyl acetate in hexane to give the corresponding compound $17(0.42 \mathrm{~g}, 28 \%)$. ${ }^{1} \mathrm{H}$ NMR (400 MHz, Chloroform-d) $\delta 7.36$ $(\mathrm{d}, J=8.3 \mathrm{~Hz}, 2 \mathrm{H}), 7.27(\mathrm{~d}, J=8.6 \mathrm{~Hz}, 2 \mathrm{H}), 7.17(\mathrm{~s}, 1 \mathrm{H}), 4.08(\mathrm{~s}, 2 \mathrm{H}), 3.51(\mathrm{~s}, 3 \mathrm{H})$.

To a three-necked round bottom flask was added 17 (60 $\mathrm{mg}, 0.22 \mathrm{mmol})$, $\mathrm{Pd}(\mathrm{OAc})_{2}(2.5 \mathrm{mg}, 0.011 \mathrm{mmol}, 0.05$ equiv), X-Phos (10.6 mg, 0.022mmol, 0.1 equiv), potassium carbonate (60mg, $0.44 \mathrm{mmol}, 2.0$ equiv) under the atmosphere of nitrogen, followed by adding the combined solution of tetrahydrofuran $(8 \mathrm{~mL})$ and water $(2 \mathrm{~mL})$. Then a solution of (2,6-difluoropyridin-3-yl)boronic acid (42 mg, $0.28 \mathrm{mmol}, 1.2$ equiv) in THF $(2 \mathrm{~mL})$ was added dropwise. The resulting mixture was stirred at $60{ }^{\circ} \mathrm{C}$ for $2 \mathrm{~h}$, after cooling, the reaction mixture was filtered and the filtrate was extracted with ethyl acetate $(15 \mathrm{~mL} \times 3)$ and the combined organic layers were washed with brine (10 $\mathrm{mL}$ ), dried over anhydrous $\mathrm{Na}_{2} \mathrm{SO}_{4}$, filtered and concentrated to give the crude product, which was further purified by column chromatography to afford compound 10k as powder.

\section{5. synthesis of intermediates $18 \mathrm{~h}-18 \mathrm{n}$}

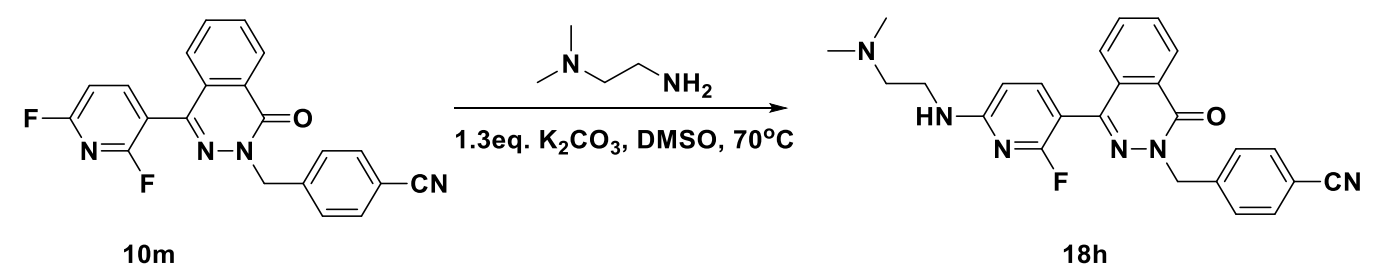

A mixture of $10 \mathrm{~m}(0.374 \mathrm{~g}, 1 \mathrm{mmol}), \mathrm{N}, \mathrm{N}$-dimethylethane-1,2-diamine $(73 \mathrm{mg}$, $1 \mathrm{mmol}, 1.0$ equiv ) and $\mathrm{K}_{2} \mathrm{CO}_{3}(175 \mathrm{mg}, 1.3 \mathrm{mmol}, 1.3$ equiv) in DMSO $(5 \mathrm{~mL})$ was 
allowed to react under air atmosphere. The reaction mixture was heated to $70^{\circ} \mathrm{C}$ for 3 h. After reaction, the reaction mixture was added to brine $(15 \mathrm{~mL})$ and extracted with ethyl acetate $(15 \mathrm{~mL} \times 3)$. The solvent was concentrated under vacuum and the product was isolated by short chromatography on a silica gel (200-300 mesh) column eluting with $50 \%$ ethyl acetate in hexane to give the desired product $\mathbf{1 8 h} .{ }^{1} \mathrm{H}$ NMR $(400 \mathrm{MHz}$, Chloroform-d) $\delta 8.49-8.40(\mathrm{~m}, 1 \mathrm{H}), 7.79-7.71(\mathrm{~m}, 2 \mathrm{H}), 7.57(\mathrm{q}, J=8.5 \mathrm{~Hz}, 6 \mathrm{H})$, $6.35(\mathrm{dd}, J=8.2,1.9 \mathrm{~Hz}, 1 \mathrm{H}), 6.17(\mathrm{~d}, J=5.6 \mathrm{~Hz}, 1 \mathrm{H}), 5.46(\mathrm{~s}, 2 \mathrm{H}), 3.43(\mathrm{q}, J=6.0$ $\mathrm{Hz}, 2 \mathrm{H}), 2.45$ (t, $J=6.5 \mathrm{~Hz}, 2 \mathrm{H}), 2.27(\mathrm{~s}, 6 \mathrm{H})$.

$18 \mathbf{i}$

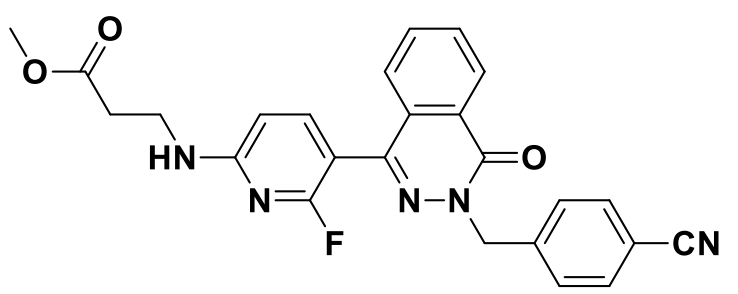

${ }^{1} \mathrm{H}$ NMR (400 MHz, Chloroform-d) $\delta 8.53-8.47$ (m, 1H), $7.84-7.77$ (m, 2H), $7.66-$ $7.62(\mathrm{~m}, 2 \mathrm{H}), 7.62-7.56(\mathrm{~m}, 4 \mathrm{H}), 6.41(\mathrm{dd}, J=8.2,1.8 \mathrm{~Hz}, 1 \mathrm{H}), 5.49(\mathrm{~s}, 2 \mathrm{H}), 5.35(\mathrm{t}$, $J=6.3 \mathrm{~Hz}, 1 \mathrm{H}), 3.75(\mathrm{~s}, 3 \mathrm{H}), 3.72-3.77(\mathrm{~m}, 2 \mathrm{H}), 2.72(\mathrm{t}, J=6.0 \mathrm{~Hz}, 2 \mathrm{H})$.

\section{8j}

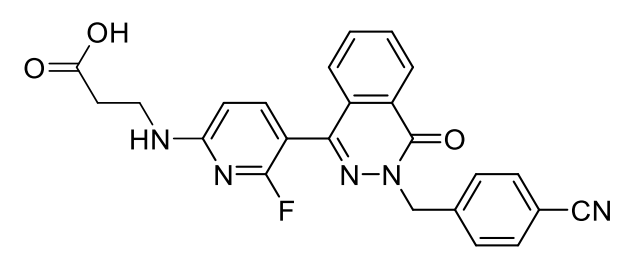

${ }^{1} \mathrm{H}$ NMR (400 MHz, Chloroform-d) $\delta 8.53-8.47(\mathrm{~m}, 1 \mathrm{H}), 7.83-7.79(\mathrm{~m}, 2 \mathrm{H}), 7.68-$ $7.55(\mathrm{~m}, 6 \mathrm{H}), 6.41(\mathrm{dd}, J=8.2,1.8 \mathrm{~Hz}, 1 \mathrm{H}), 5.47(\mathrm{~s}, 2 \mathrm{H}), 5.36(\mathrm{t}, J=6.2 \mathrm{~Hz}, 1 \mathrm{H}), 3.69$ (q, $J=6.1 \mathrm{~Hz}, 2 \mathrm{H}), 2.61(\mathrm{t}, J=6.0 \mathrm{~Hz}, 2 \mathrm{H})$.

\section{$18 \mathrm{k}$}

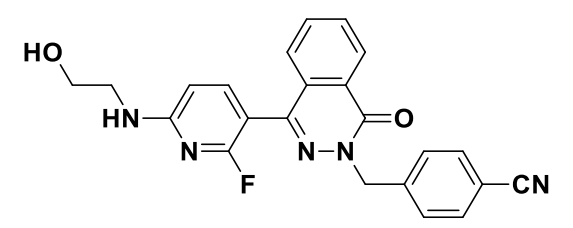

${ }^{1} \mathrm{H}$ NMR (400 MHz, Methanol-d4) $\delta 8.47-8.42(\mathrm{~m}, 1 \mathrm{H}), 7.95-7.89(\mathrm{~m}, 2 \mathrm{H}), 7.75-$ $7.71(\mathrm{~m}, 2 \mathrm{H}), 7.69-7.58(\mathrm{~m}, 4 \mathrm{H}), 6.55(\mathrm{dd}, J=8.3,1.9 \mathrm{~Hz}, 1 \mathrm{H}), 5.53(\mathrm{~s}, 2 \mathrm{H}), 3.76(\mathrm{t}$, $J=5.8 \mathrm{~Hz}, 2 \mathrm{H}), 3.52(\mathrm{t}, J=5.8 \mathrm{~Hz}, 2 \mathrm{H})$. 
181

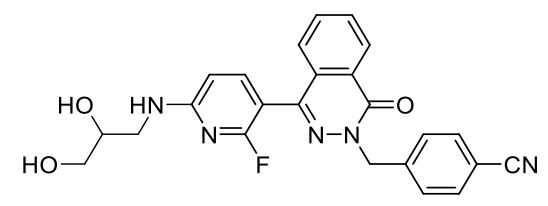

${ }^{1} \mathrm{H}$ NMR (400 MHz, Chloroform-d) $\delta 8.53-8.47(\mathrm{~m}, 1 \mathrm{H}), 7.85-7.79(\mathrm{~m}, 2 \mathrm{H}), 7.65-$ $7.54(\mathrm{~m}, 6 \mathrm{H}), 6.47(\mathrm{dd}, J=8.2,1.7 \mathrm{~Hz}, 1 \mathrm{H}), 5.49(\mathrm{~s}, 2 \mathrm{H}), 5.18(\mathrm{t}, J=6.0 \mathrm{~Hz}, 1 \mathrm{H}), 3.94-$ $4.00(\mathrm{~m}, 1 \mathrm{H}), 3.84-3.53(\mathrm{~m}, 4 \mathrm{H}), 2.91(\mathrm{~s}, 1 \mathrm{H}), 2.66(\mathrm{~s}, 1 \mathrm{H})$.

\section{$18 \mathrm{~m}$}

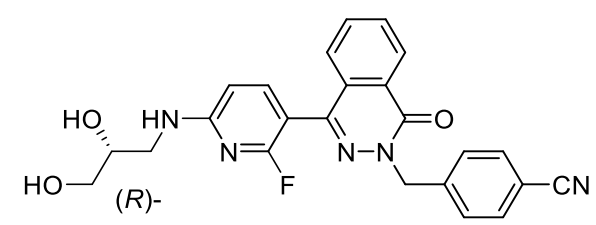

${ }^{1} \mathrm{H}$ NMR (400 MHz, Chloroform-d) $\delta 8.54-8.48(\mathrm{~m}, 1 \mathrm{H}), 7.86-7.78$ (m, 2H), $7.66-$ $7.56(\mathrm{~m}, 6 \mathrm{H}), 6.48(\mathrm{dd}, J=8.2,1.7 \mathrm{~Hz}, 1 \mathrm{H}), 5.50(\mathrm{~s}, 2 \mathrm{H}), 5.19(\mathrm{t}, J=6.1 \mathrm{~Hz}, 1 \mathrm{H}), 3.94-$ $4.00(\mathrm{~m}, 1 \mathrm{H}), 3.82-3.51(\mathrm{~m}, 4 \mathrm{H}), 2.92(\mathrm{~s}, 1 \mathrm{H}), 2.68(\mathrm{~s}, 1 \mathrm{H})$.

\section{$18 n$}

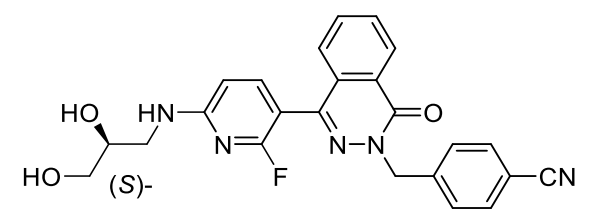

${ }^{1} \mathrm{H}$ NMR (400 MHz, Chloroform-d) $\delta 8.52-8.45$ (m, 1H), 7.83 - $7.75(\mathrm{~m}, 2 \mathrm{H}), 7.64-$ $7.55(\mathrm{~m}, 6 \mathrm{H}), 6.46(\mathrm{dd}, J=8.3,1.7 \mathrm{~Hz}, 1 \mathrm{H}), 5.48(\mathrm{~s}, 2 \mathrm{H}), 5.17(\mathrm{t}, J=6.1 \mathrm{~Hz}, 1 \mathrm{H})$, 3.95-4.00 (m, 1H), $3.84-3.51(\mathrm{~m}, 4 \mathrm{H}), 2.91(\mathrm{~s}, 1 \mathrm{H}), 2.67(\mathrm{~s}, 1 \mathrm{H})$. 
Characterization of 101, 10m, 18a, 18b, 18d, 18e, 18g, 19a,19b, 19c, 19d, 19e, 19f, 19g, 19h ( ${ }^{1} \mathrm{HNMR}$ spectra ${ }^{13} \mathrm{CNMR}$ spectra were attached)

2-(4-chlorobenzyl)-4-(2,6-difluoropyridin-3-yl)phthalazin-1(2H)-one (10l)

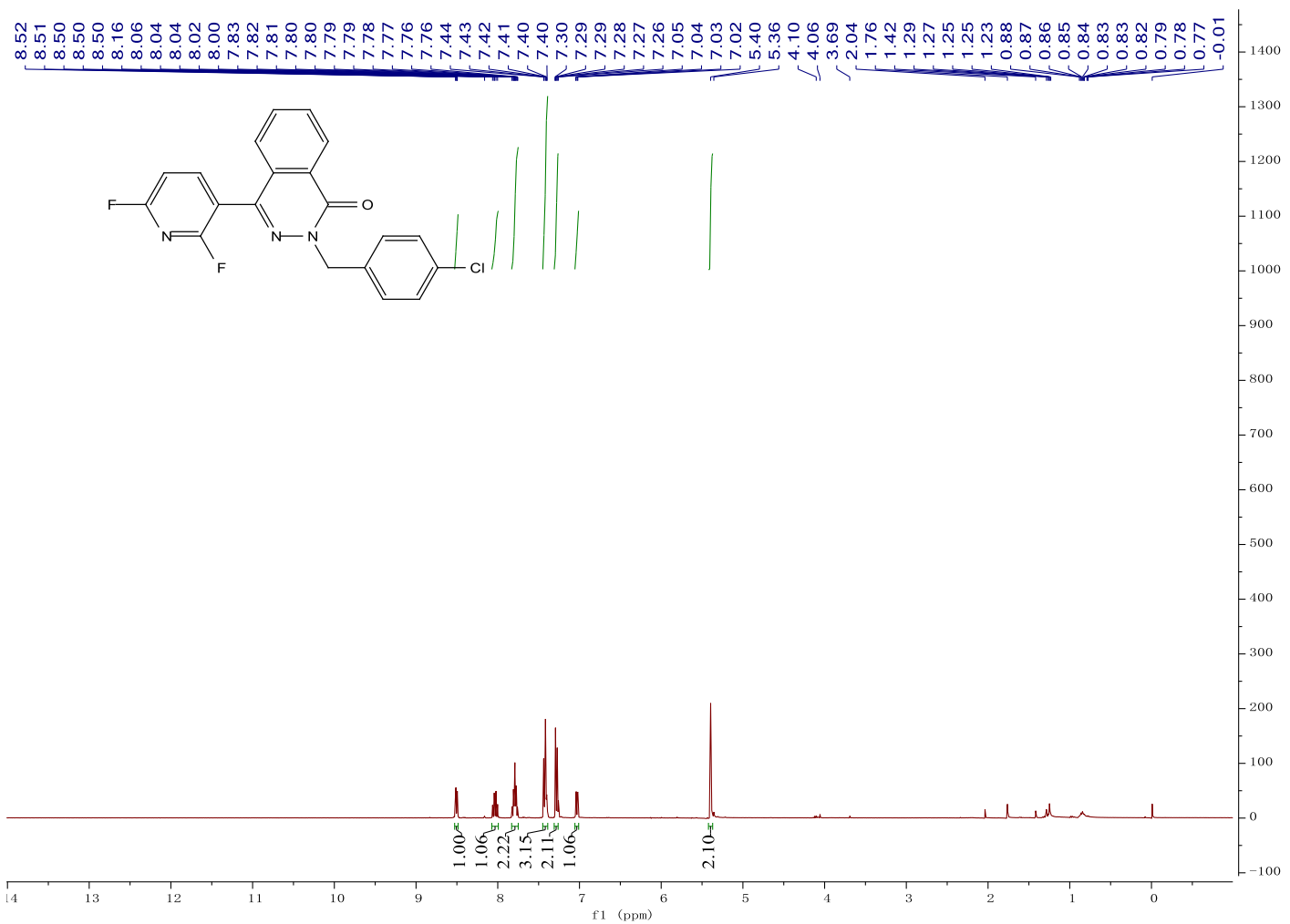

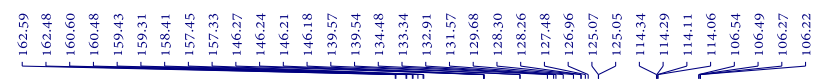

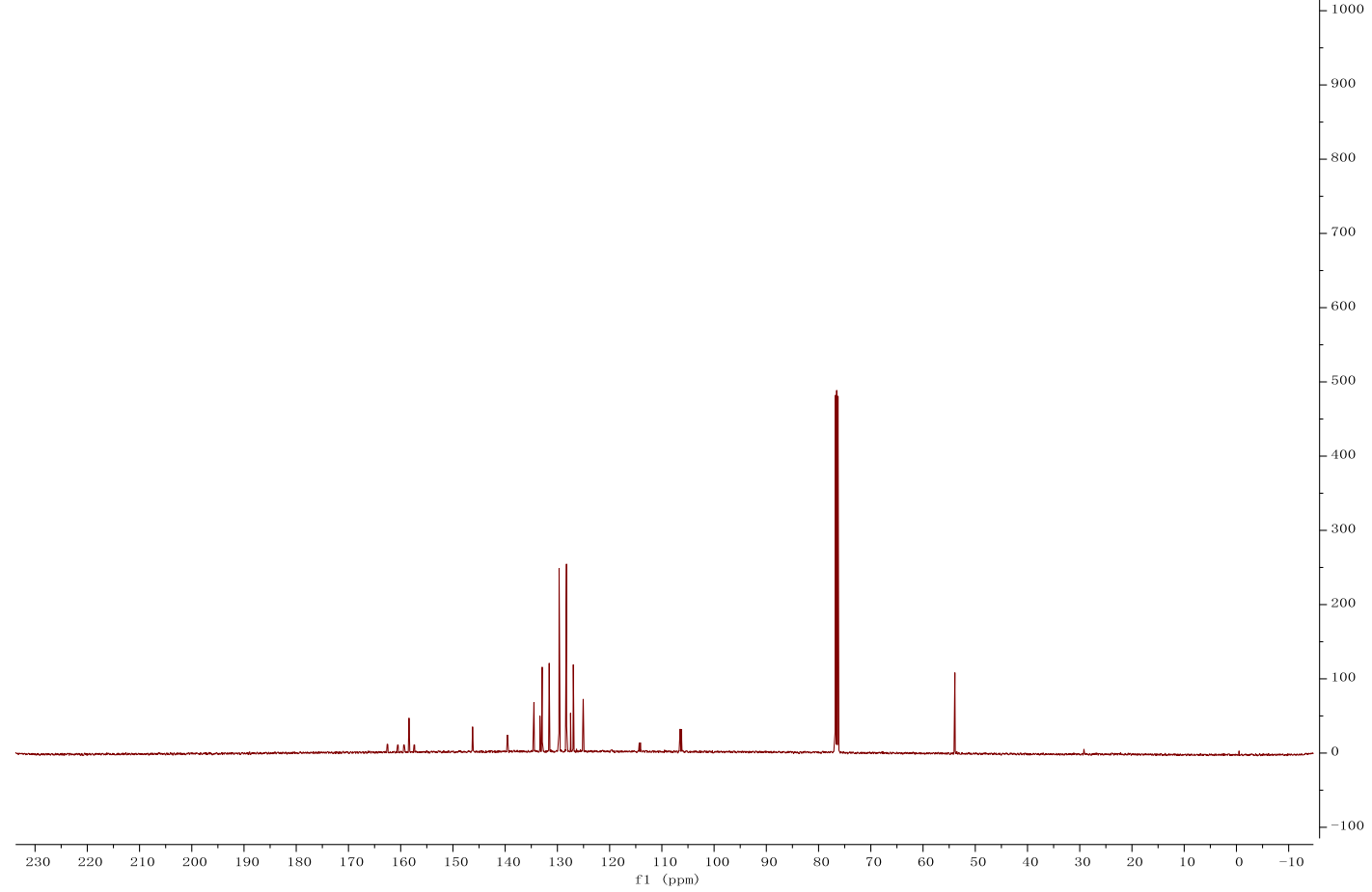




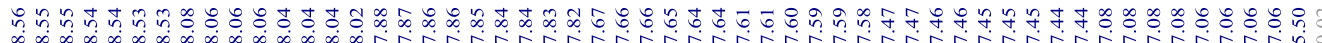

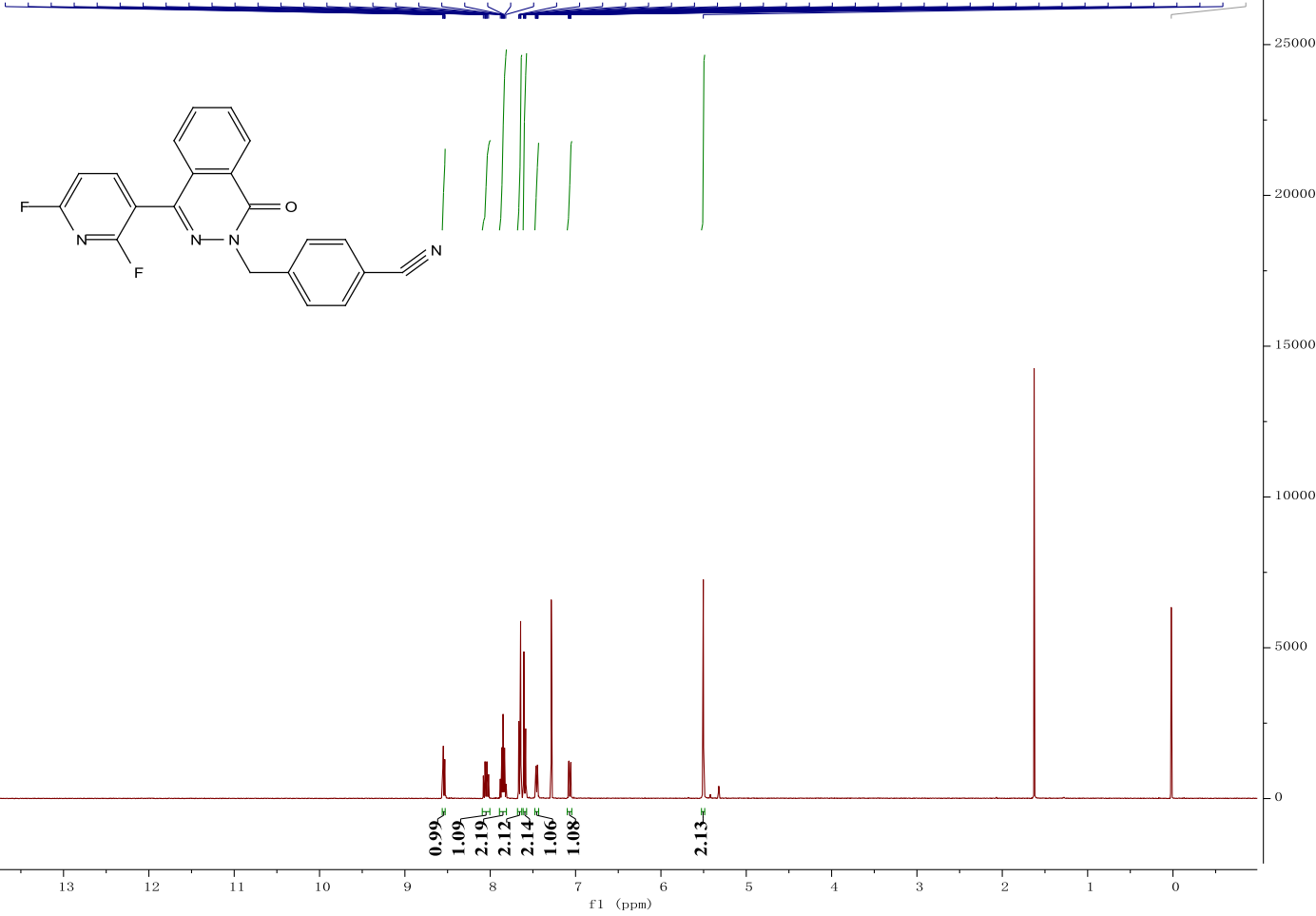

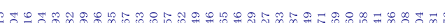

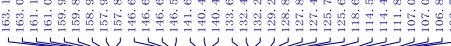

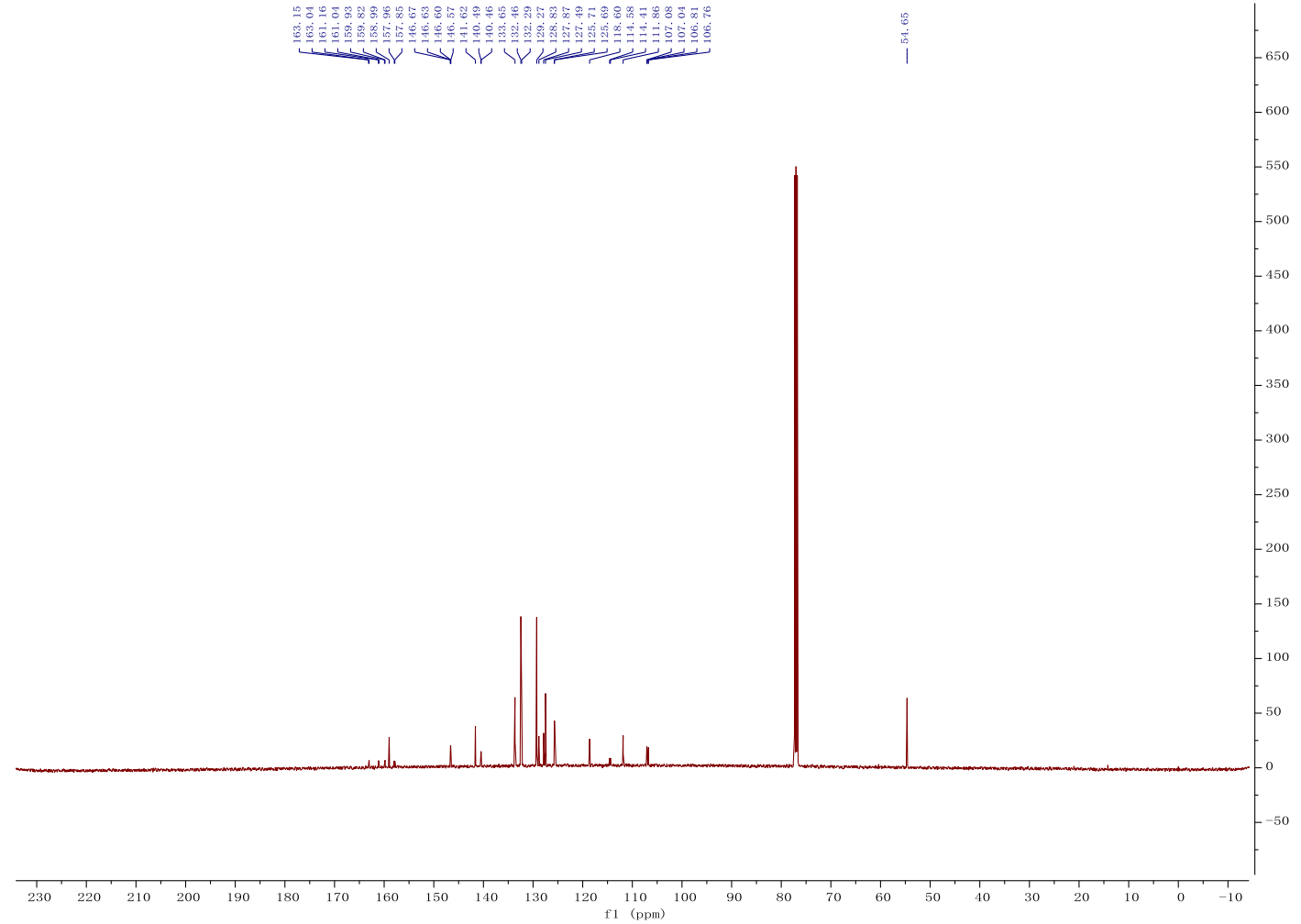


4-((4-(2-fluoro-6-methylpyridin-3-yl)-1-oxophthalazin-2(1H)-yl)methyl)benzonitrile (18a)
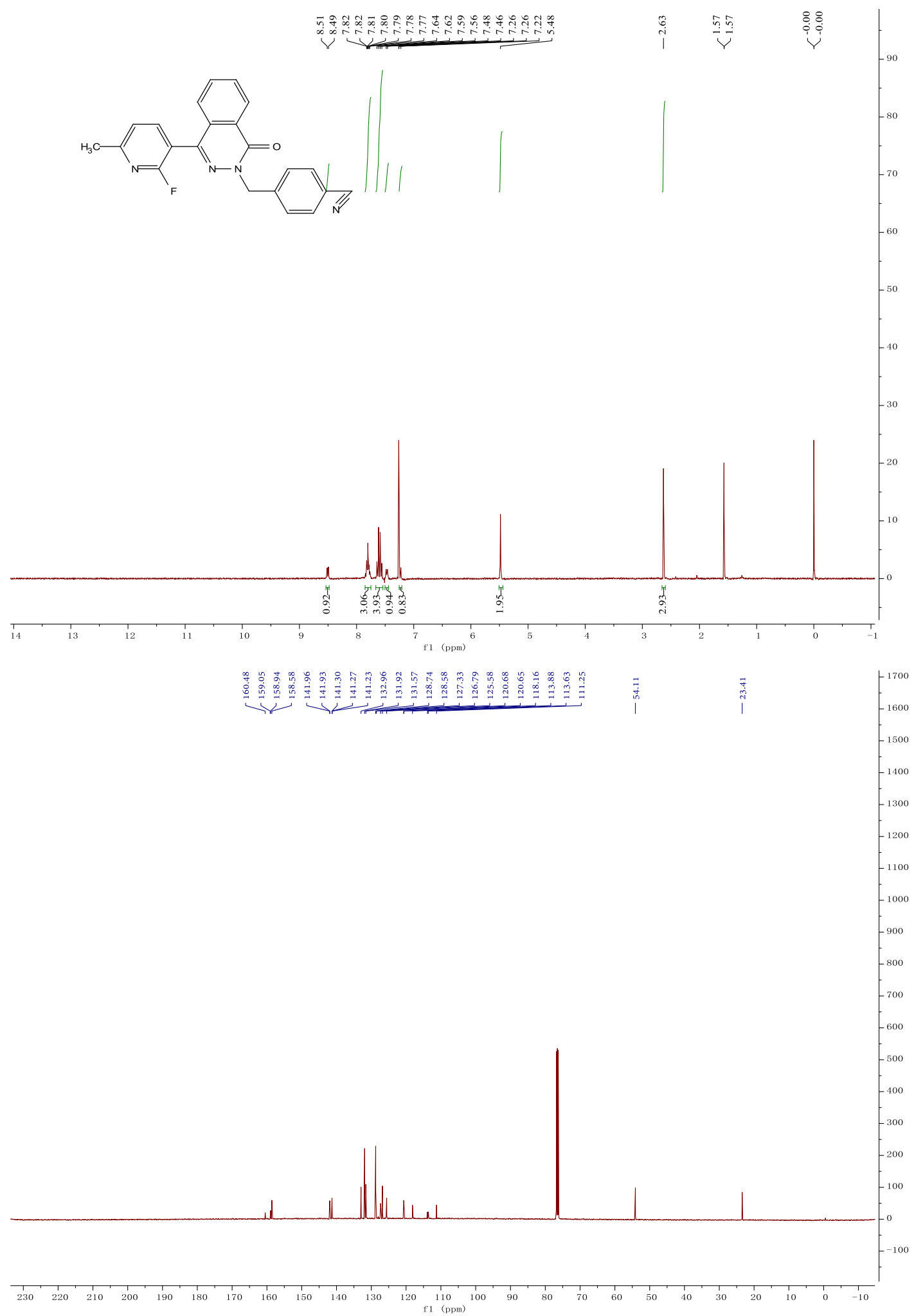
4-((4-(6-amino-2-fluoropyridin-3-yl)-1-oxophthalazin-2(1H)-yl)methyl)benzonitrile (18b)

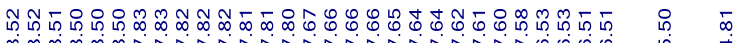

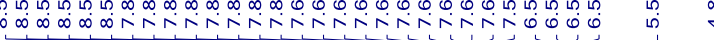

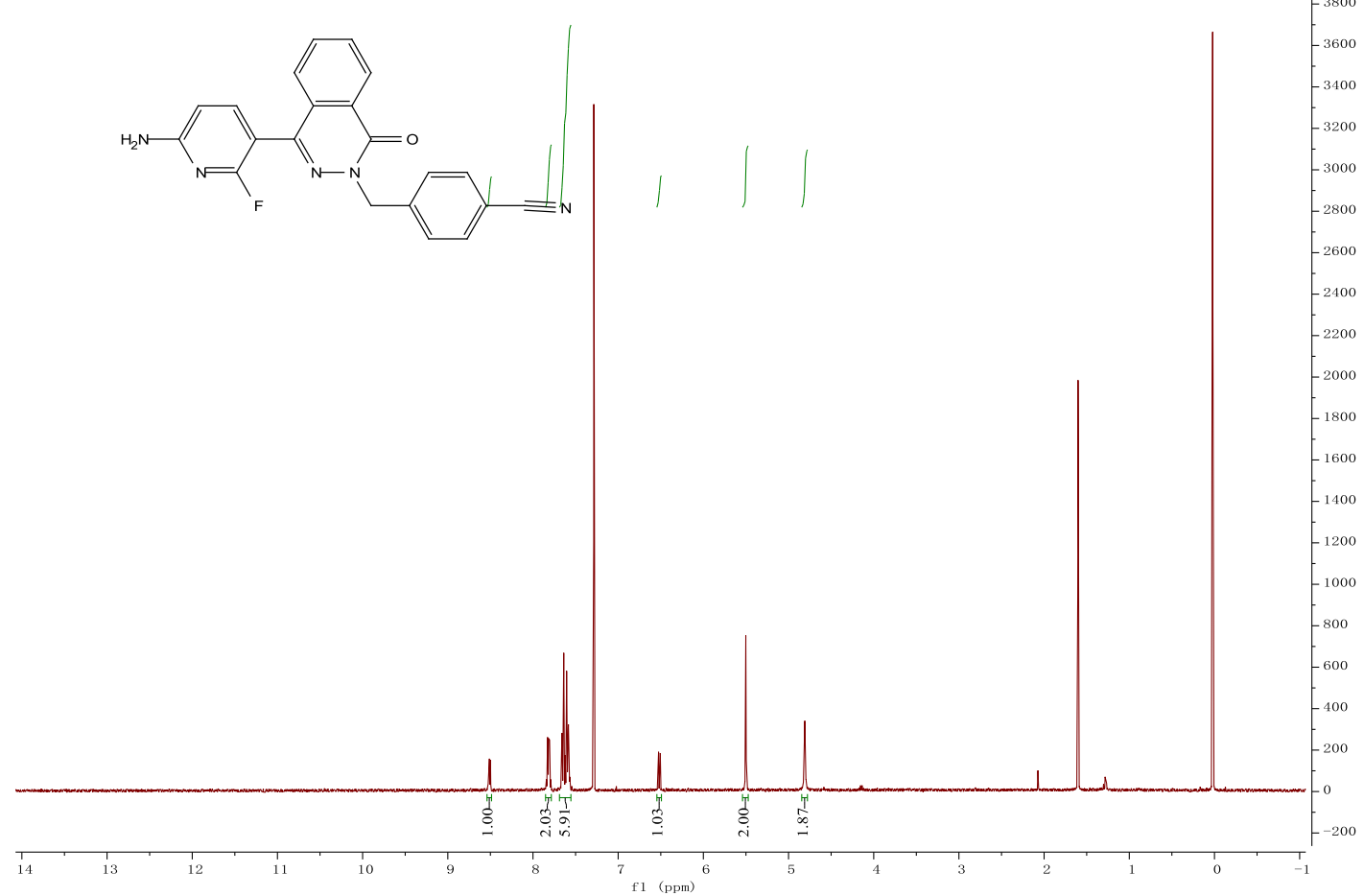

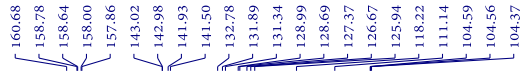

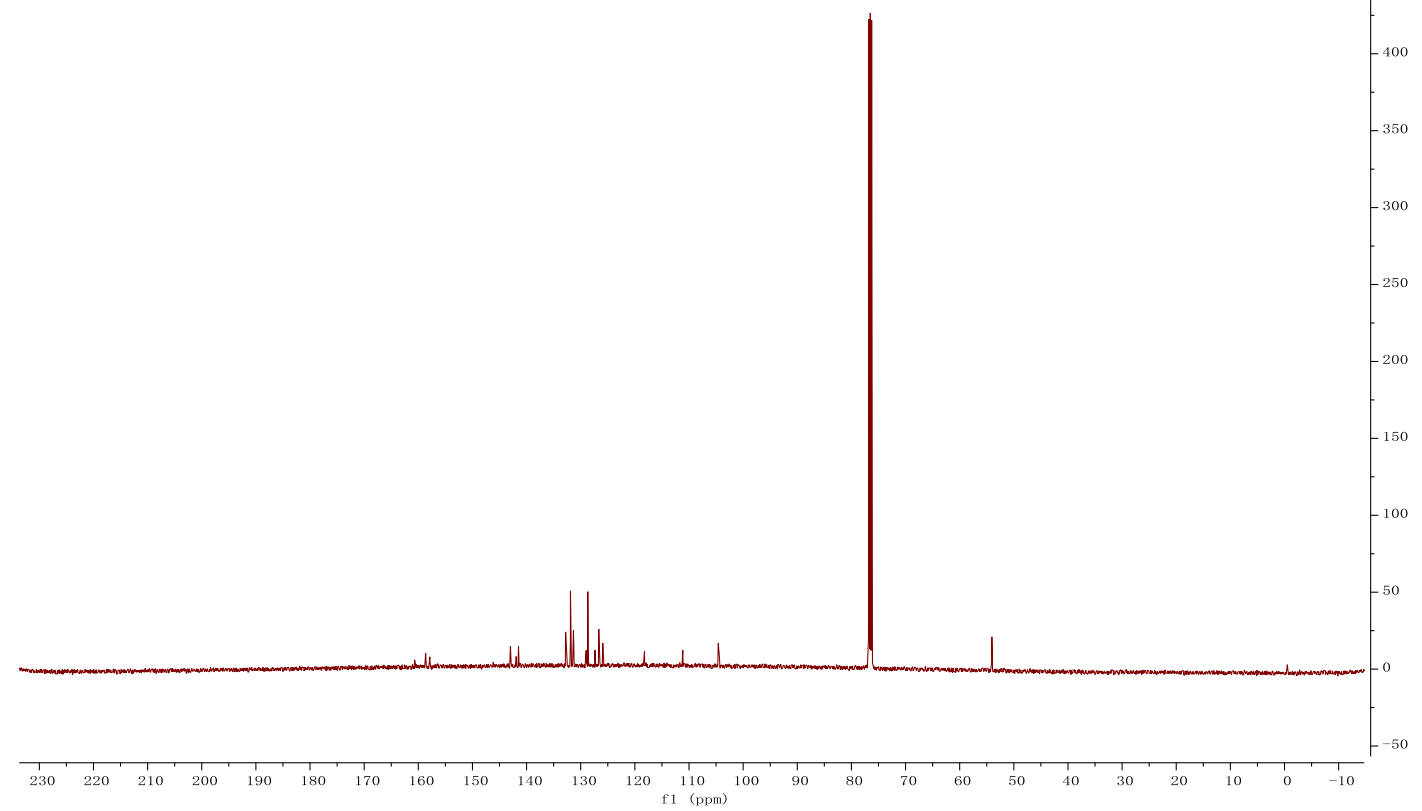


4-((4-(2-fluoro-6-(methylamino)pyridin-3-yl)-1-oxophthalazin-2(1H)yl)methyl)benzonitrile (18d)
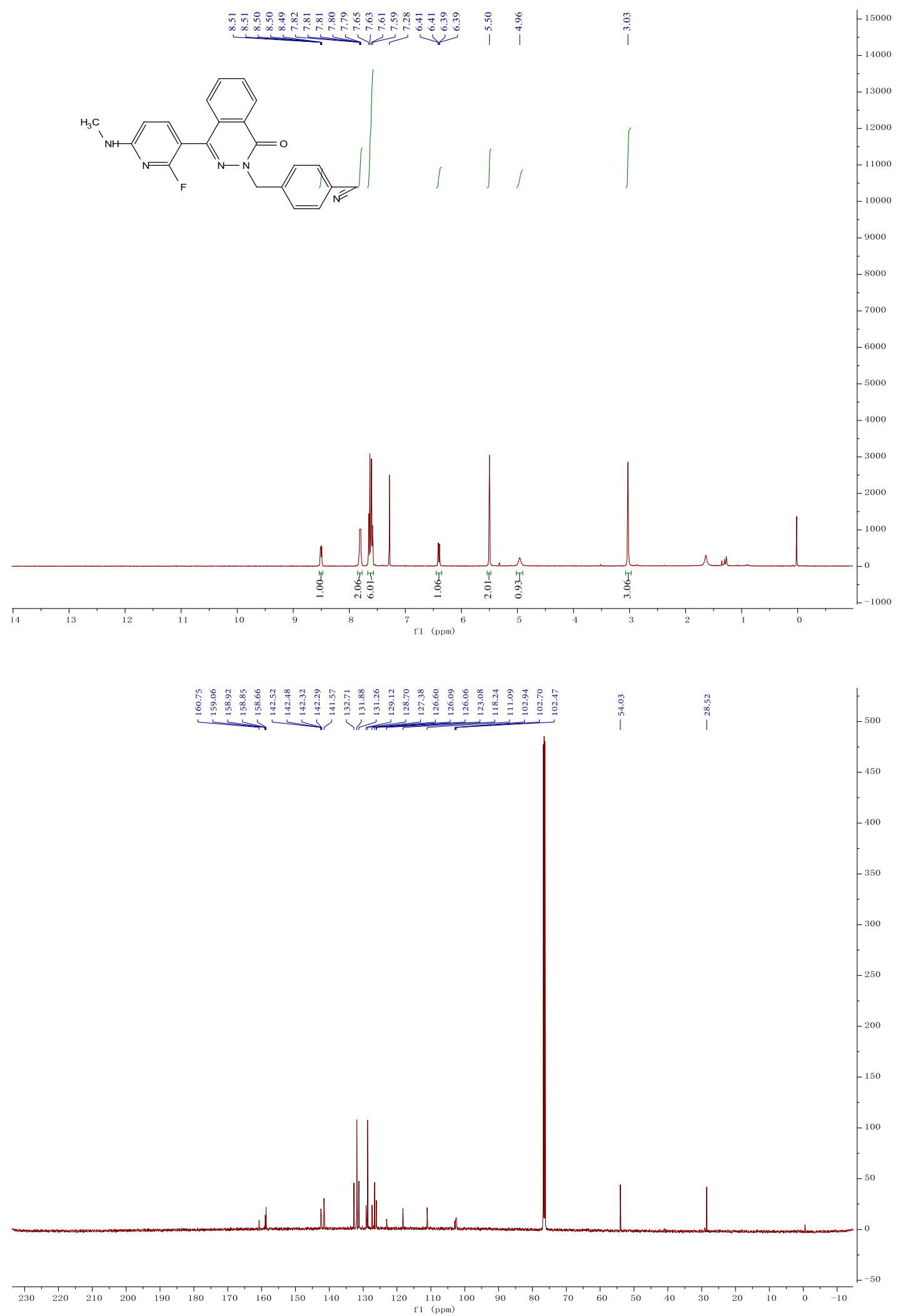
4-((4-(6-(dimethylamino)-2-fluoropyridin-3-yl)-1-oxophthalazin-2(1 H)yl)methyl)benzonitrile (18e)
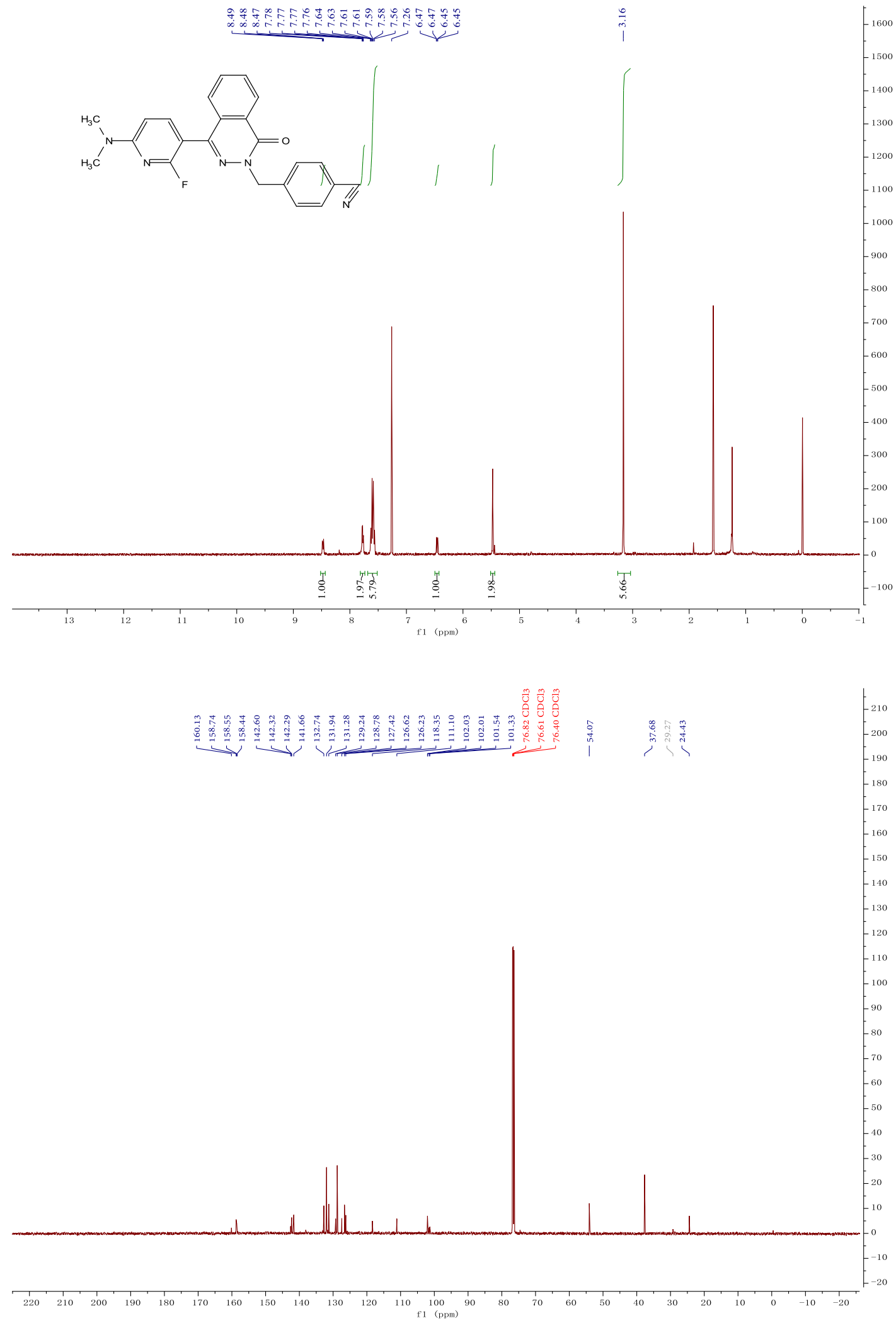
4-((4-(2-fluoro-6-((2-methoxyethyl)amino)pyridin-3-yl)-1-oxophthalazin-2(1H)yl)methyl)benzonitrile (18g)

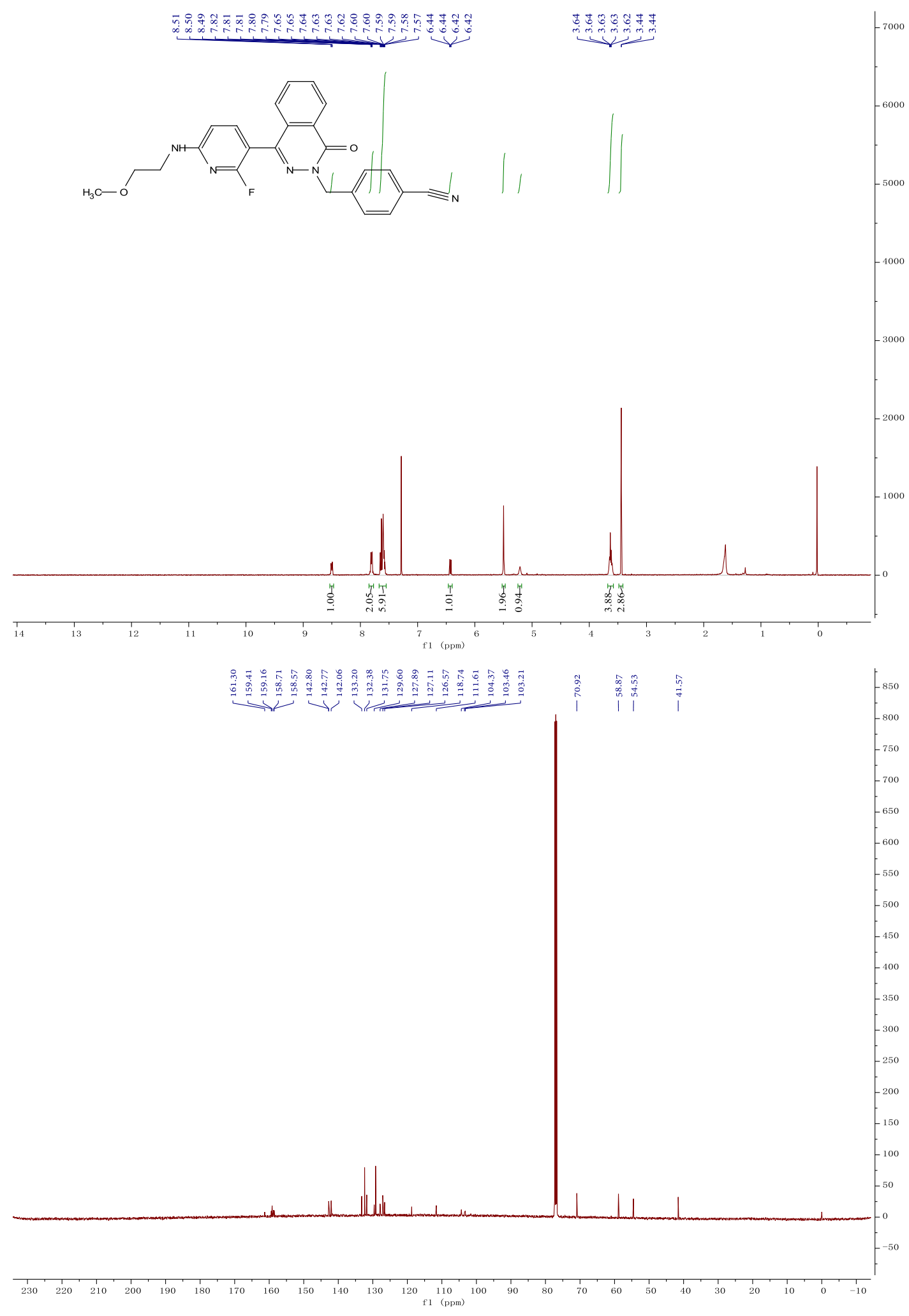


4-((4-(5-chloro-2-fluoro-6-((2-methoxyethyl)amino)pyridin-3-yl)-1-oxophthalazin-2(1H)yl)methyl)benzonitrile (19a)

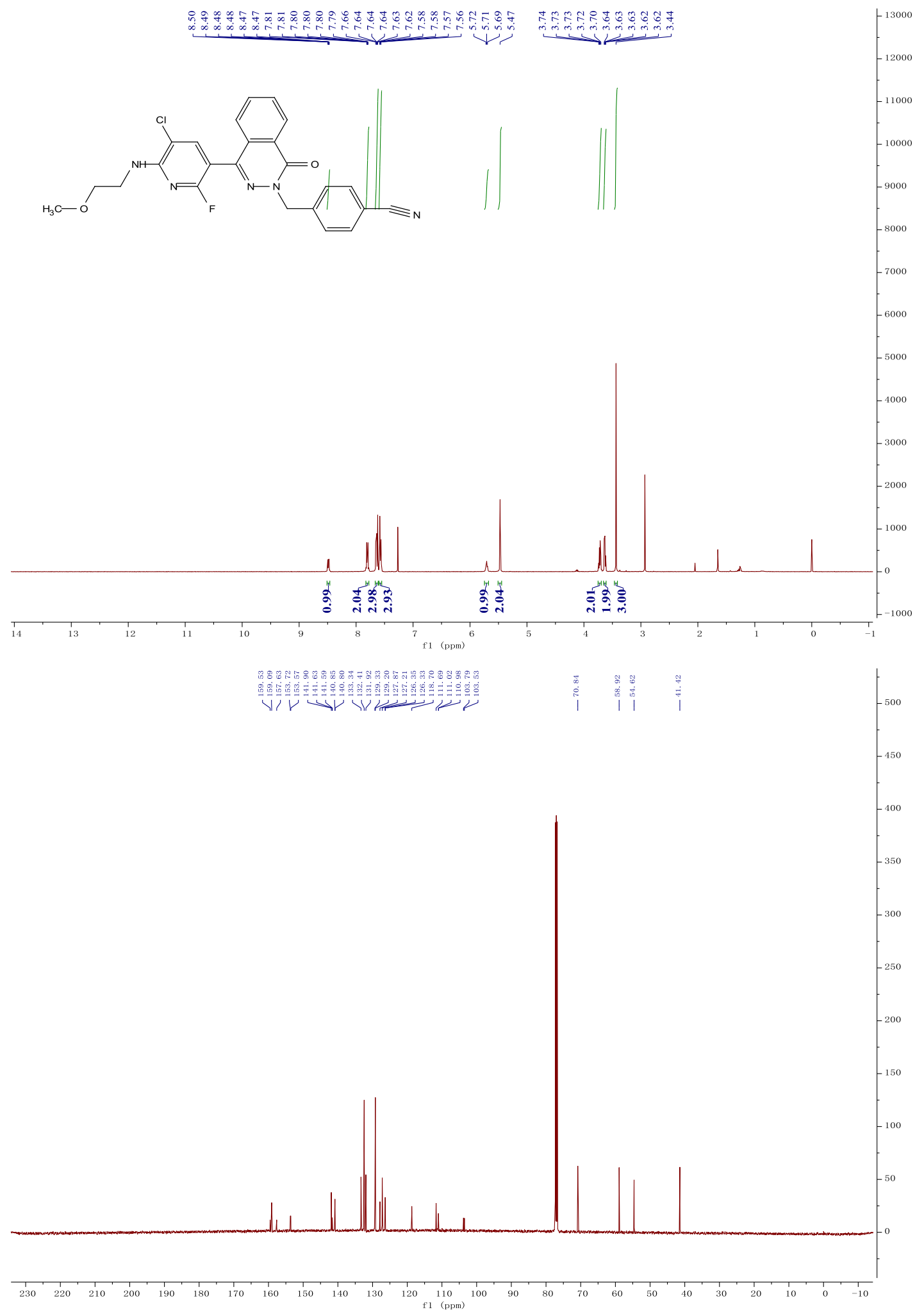


4-((4-(5-chloro-6-((2-(dimethylamino)ethyl)amino)-2-fluoropyridin-3-yl)-1oxophthalazin-2(1H)-yl)methyl)benzonitrile (19b)

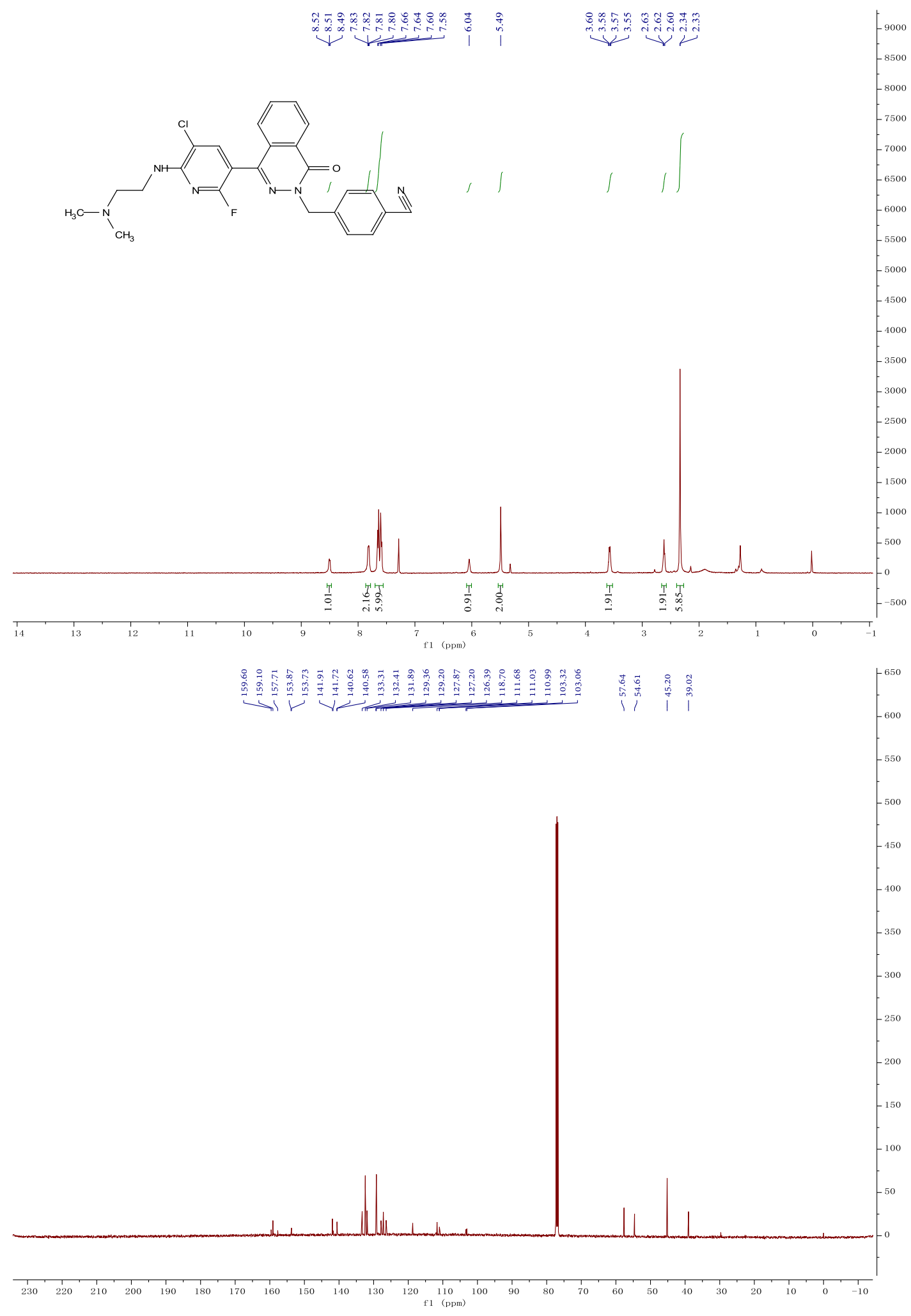


methyl

3-((3-chloro-5-(3-(4-cyanobenzyl)-4-oxo-3,4-dihydrophthalazin-1-yl)-6-

fluoropyridin-2-yl)amino)propanoate (19c)

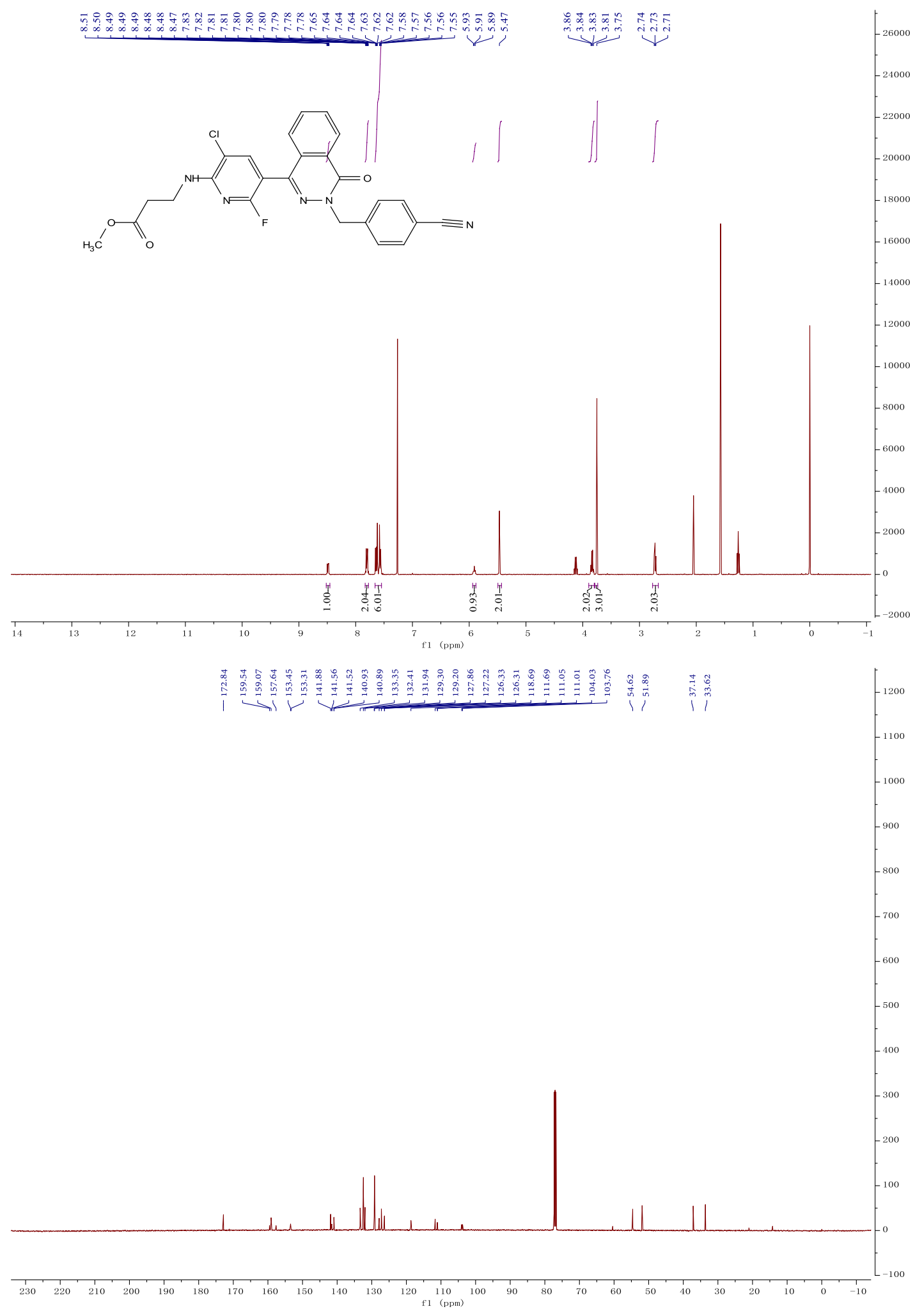


3-((3-chloro-5-(3-(4-cyanobenzyl)-4-oxo-3,4-dihydrophthalazin-1-yl)-6-fluoropyridin-2yl)amino)propanoic acid (19d)

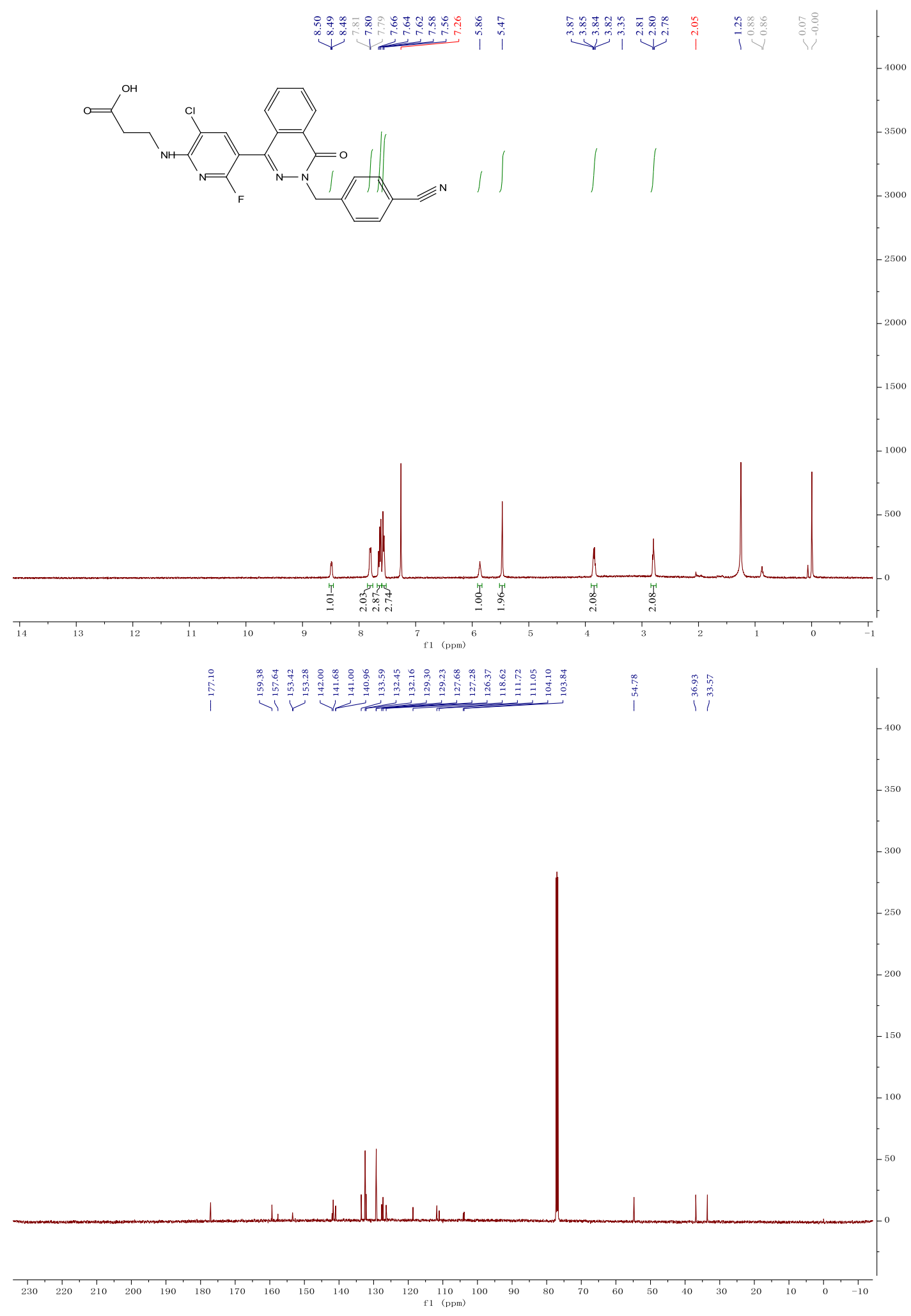


4-((4-(5-chloro-2-fluoro-6-((2-hydroxyethyl)amino)pyridin-3-yl)-1-oxophthalazin-2(1 H)yl)methyl)benzonitrile (19e)

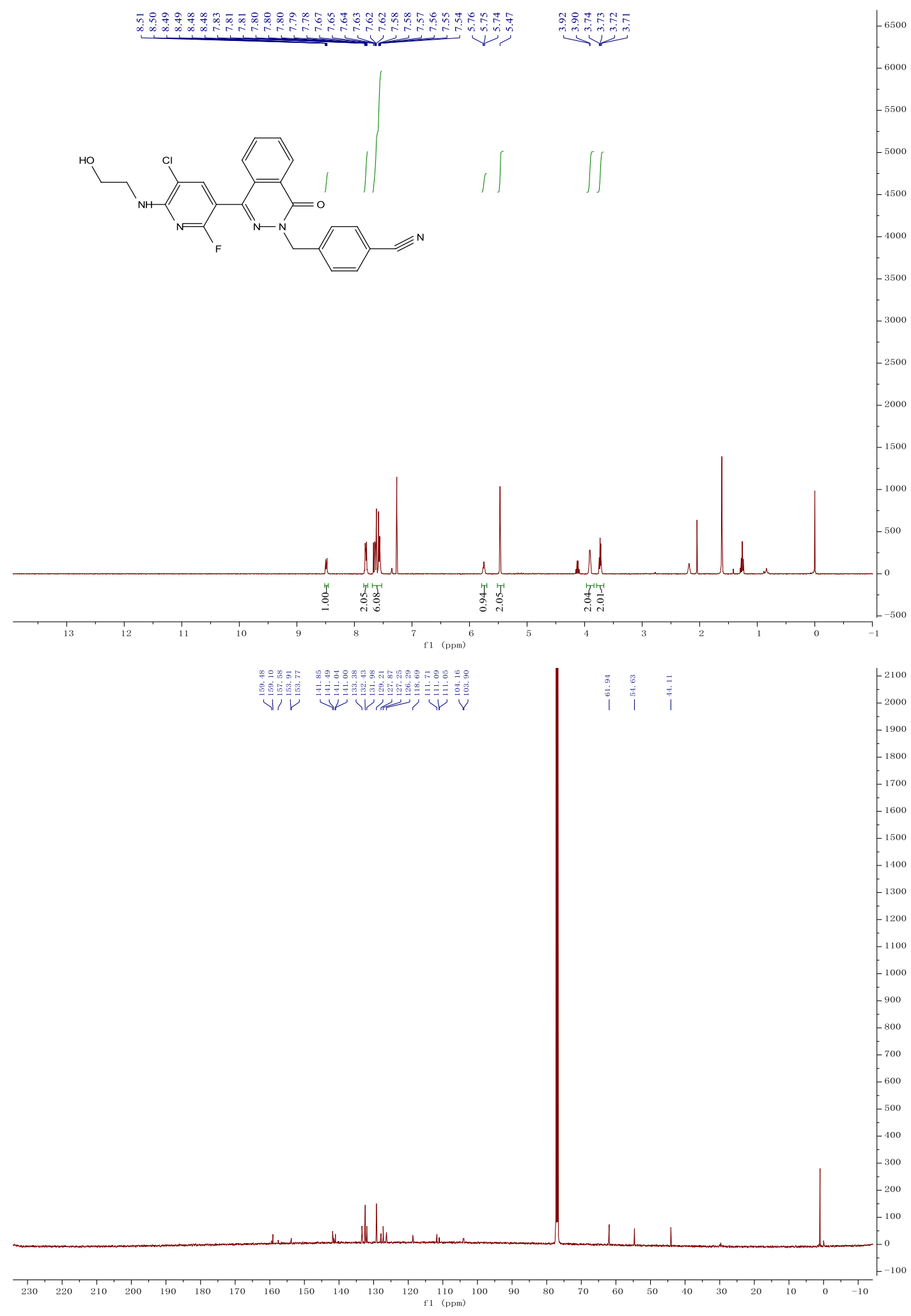


4-((4-(5-chloro-6-((2,3-dihydroxypropyl)amino)-2-fluoropyridin-3-yl)-1-oxophthalazin2(1H)-yl)methyl)benzonitrile (19f)
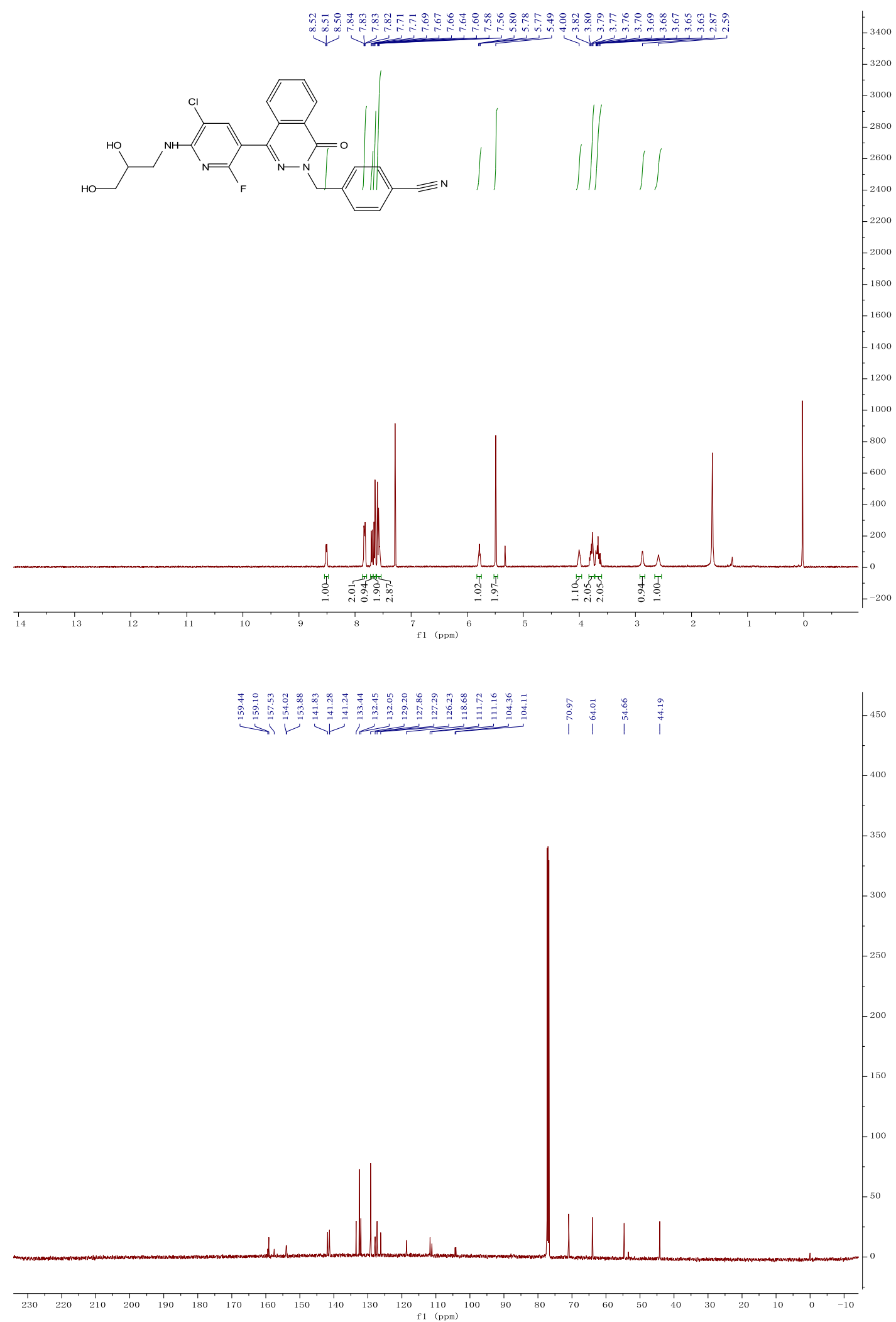
(S)-4-((4-(5-chloro-6-((2,3-dihydroxypropyl)amino)-2-fluoropyridin-3-yl)-1oxophthalazin-2(1 H)-yl)methyl)benzonitrile (19g)

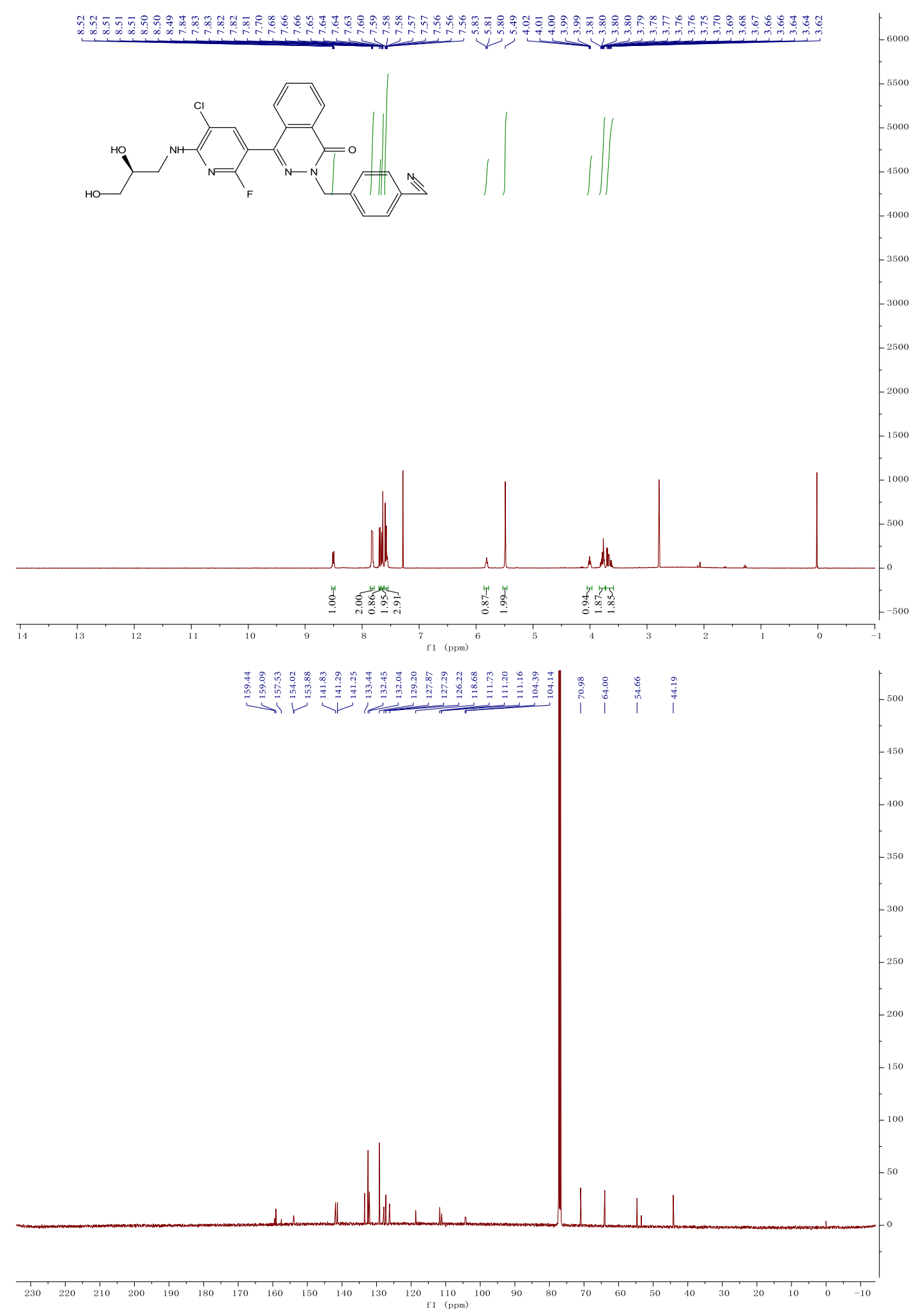


(R)-4-((4-(5-chloro-6-((2,3-dihydroxypropyl)amino)-2-fluoropyridin-3-yl)-1oxophthalazin-2(1H)-yl)methyl)benzonitrile (19h)

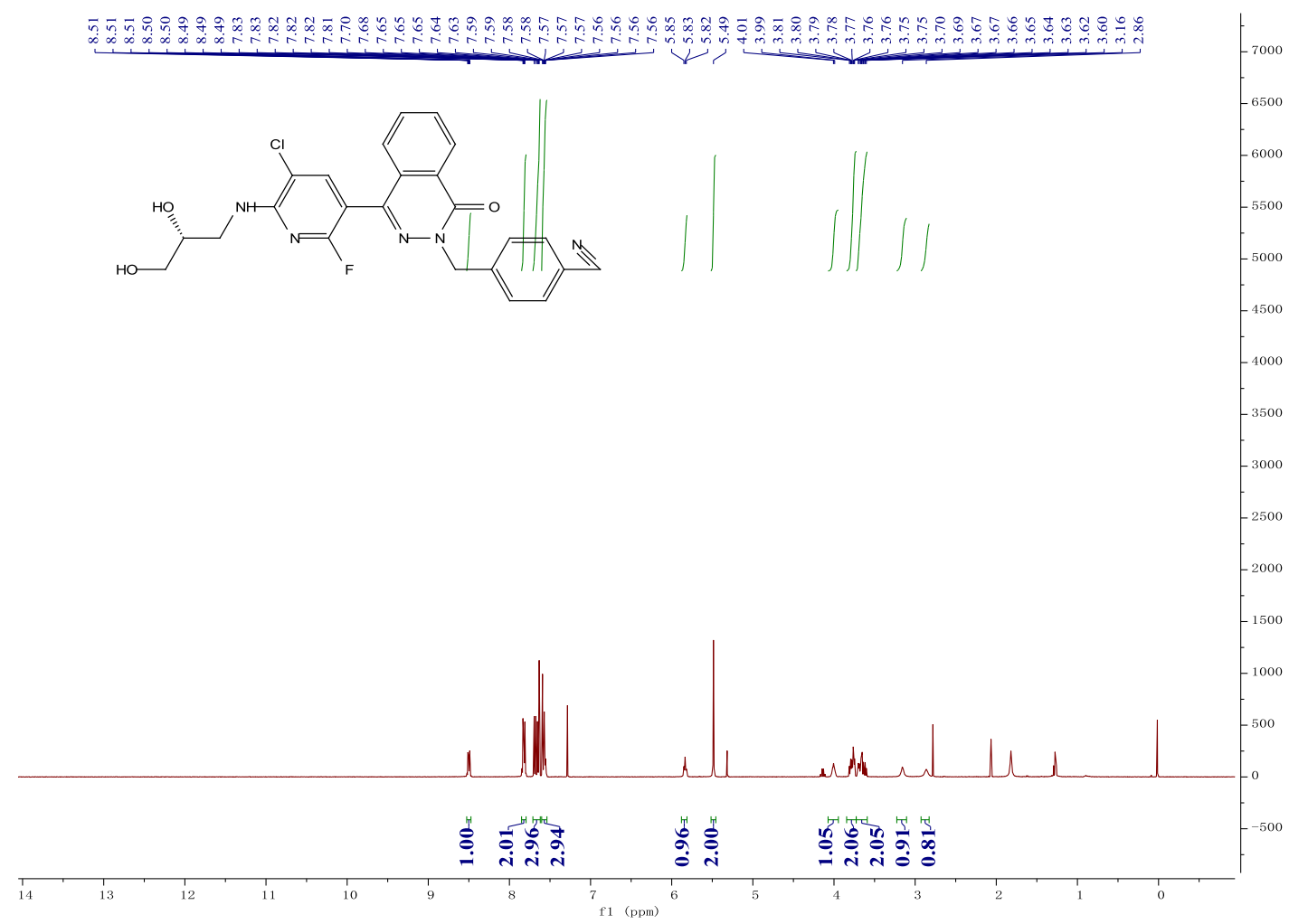




\section{HPLC purity control of selected final compounds.}

Purity of all of the selected final compounds was determined by reverse-phase high performance liquid chromatography (HPLC) analysis to be $>95 \%$. HPLC instrument: Agilent 1260 series LC system (Agilent Eclipse XBD-C18, 5 $\mu \mathrm{m}, 4.6 \mathrm{~mm} \times 150 \mathrm{~mm}$, $30{ }^{\circ} \mathrm{C}$, UV $254 \mathrm{nM}$, injection volume $=3 \mu \mathrm{L}$, flow rate $=0.7 \mathrm{~mL} / \mathrm{min}$ ) with using a listed gradient (mobile phase $\mathrm{A}, \mathrm{H}_{2} \mathrm{O}$ (containing $0.1 \% \mathrm{HCOOH}$ ); mobile phase $\mathrm{B}$, Methanol) for $25 \mathrm{~min}$. (Table $\mathbf{S 4}$ ).

Table S4. Gradient of HPLC

\begin{tabular}{ccc}
\hline $\mathrm{t} / \mathrm{min}$ & $\begin{array}{c}\text { mobile phase A } \\
\mathrm{H}_{2} \mathrm{O}(0.1 \% \mathrm{HCOOH})\end{array}$ & $\begin{array}{c}\text { mobile phase B } \\
\mathrm{MeOH}\end{array}$ \\
\hline 0 & $50 \%$ & $50 \%$ \\
5 & $50 \%$ & $50 \%$ \\
10 & $25 \%$ & $75 \%$ \\
18 & $25 \%$ & $75 \%$ \\
19 & $5 \%$ & $95 \%$ \\
22 & $5 \%$ & $95 \%$ \\
23 & $50 \%$ & $50 \%$ \\
25 & $50 \%$ & $50 \%$ \\
\hline
\end{tabular}




\section{Compound 101}

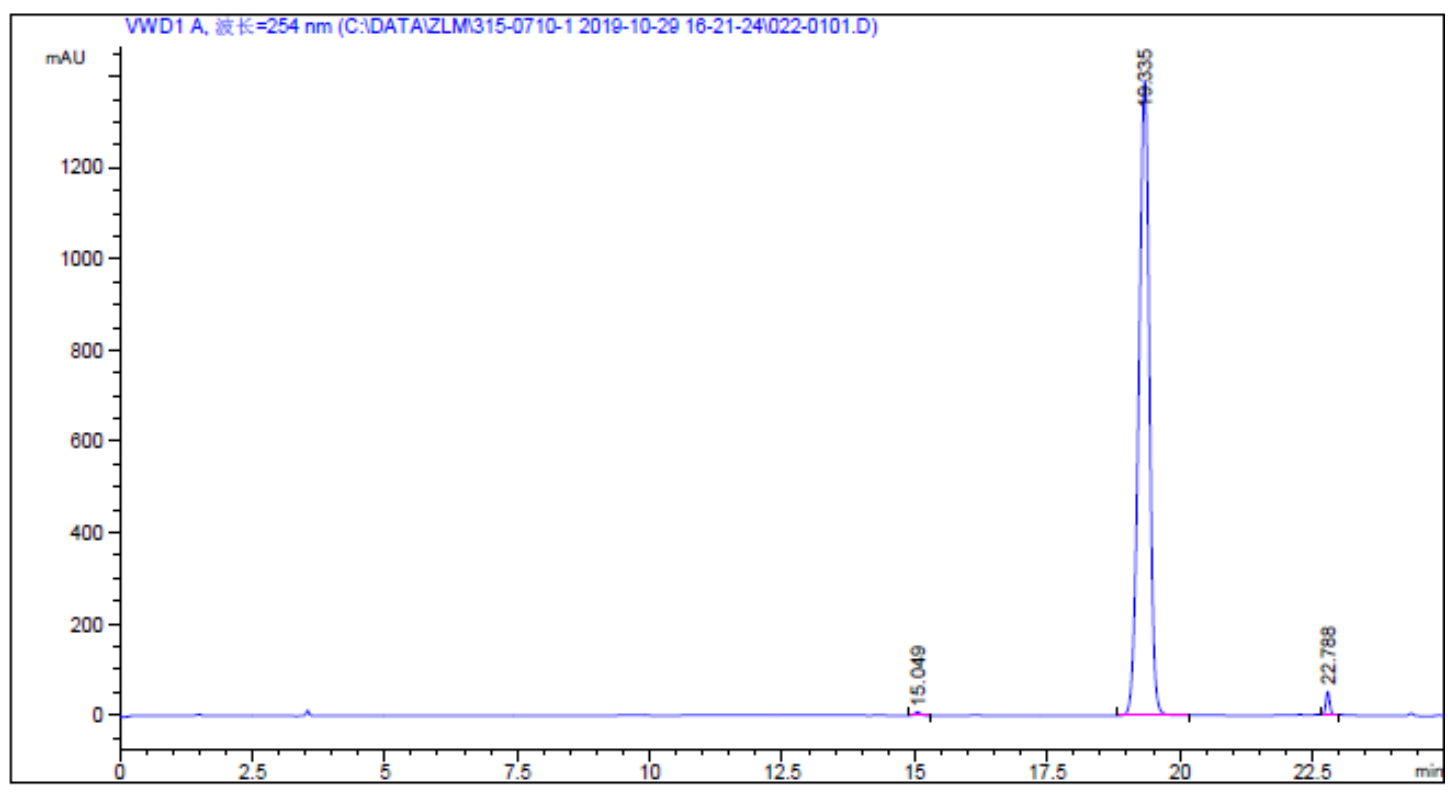

面积百分比报告

$\begin{array}{lll}\text { 排序 } & : & \text { 信号 } \\ \text { 乘积因子 } & : & 1.0000 \\ \text { 稀 释因子 } & : & 1.0000\end{array}$

内标使用乘积因子和稀释因子

信号 1: VWD1 A, 波长 $=254 \mathrm{~nm}$

\begin{tabular}{|c|c|c|c|c|c|c|}
\hline 暲 & 保留时间 & 类型 & 峰赛 & 峰面积 & 㿟离 & 桻面积 \\
\hline \# & {$[\min ]$} & & {$[\mathrm{min}]$} & $\mathrm{mAU} \times \mathrm{s}$ & {$[\mathrm{mAd}$} & 웅 \\
\hline & & & & --- & --- & \\
\hline 1 & 15. & BB & 0.1129 & 52.41301 & 7.17789 & 0.2674 \\
\hline 2 & & BB & 0.2138 & $1.92603 e 4$ & 1392.72070 & 98.2784 \\
\hline 3 & 22.788 & VB & 0.0822 & 284.99051 & 52.51780 & 1.4542 \\
\hline
\end{tabular}

总量：

$1.95977 e 4 \quad 1452.41639$ 


\section{Compound 10m}

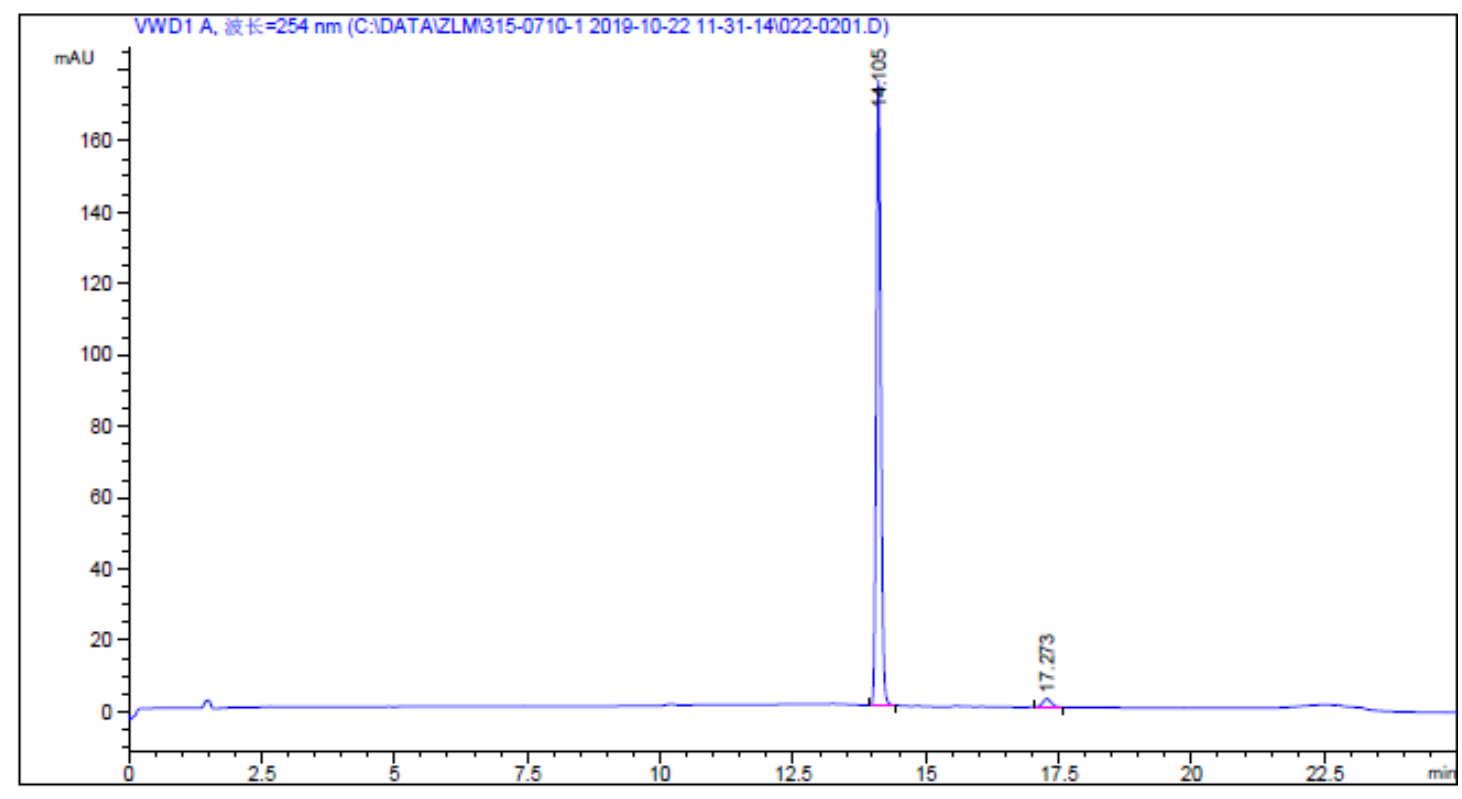

面积百分比报告

\begin{tabular}{|c|c|c|}
\hline 排序 & : & 信号 \\
\hline 乘积因子 & : & 1.0000 \\
\hline 稀释因子 & : & 1.0000 \\
\hline
\end{tabular}

内标使用乘积因子和稀释因子

信号 1: VWD1 A, 波长 $=254 \mathrm{~nm}$

\begin{tabular}{|c|c|c|c|c|c|c|}
\hline 峰 & 保留时间 & 类型 & 峰赛 & 峰面积 & 峰高 & 峰面积 \\
\hline \# & [min] & & {$[\mathrm{min}]$} & $\mathrm{mAU} \times \mathrm{s}$ & {$[\mathrm{mAd}$} & 웅 \\
\hline$\cdots$ & $-0----$ & & ---- & |------ & ----o-- & | \\
\hline 1 & 14.105 & $B B$ & 0.0917 & 1050.30884 & 175.29601 & 97.5573 \\
\hline 2 & 17.273 & $B B$ & 0.1725 & 26.29878 & 2.35486 & 2.4427 \\
\hline 总量 & $:$ & & & 1076.60762 & 177.65087 & \\
\hline
\end{tabular}




\section{Compound 18a}

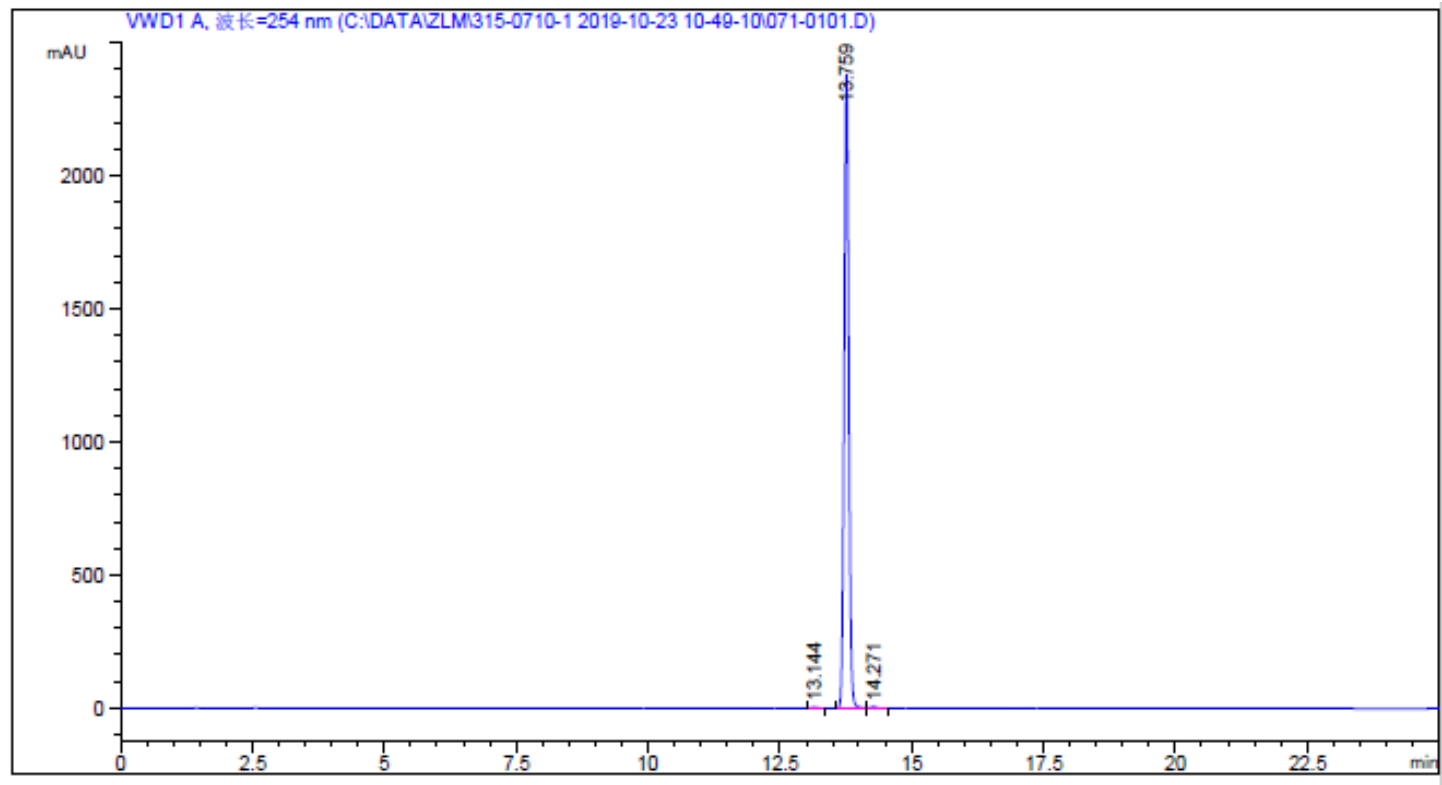

面积百分比报告

$\begin{array}{lll}\text { 排序 } & : & \text { 信号 } \\ \text { 乘积因子 } & : & 1.0000 \\ \text { 稀释因子 } & : & 1.0000\end{array}$

内标使用乘积因子和稀释因子

信号 1: VWD1 A, 波长 $=254 \mathrm{~nm}$

\begin{tabular}{|c|c|c|c|c|c|c|}
\hline 峰 & 保留时间 & 类型 & 峰赛 & 峰面积 & 峰高 & 峰面积 \\
\hline \# & [min] & & {$[\mathrm{min}]$} & mAU ${ }^{*} s$ & {$[\mathrm{mAd}$} & \%ำ \\
\hline & & & ---- & --.-- & --- & \\
\hline 1 & 13.1 & $B B$ & .0998 & 19.91358 & 3.09691 & \\
\hline 2 & & BV & .0943 & $1.44875 e 4$ & 2381.67993 & 99.5 \\
\hline 3 & 14.271 & VB & 0.1069 & 42.04581 & 5.86401 & 0.2890 \\
\hline
\end{tabular}

总量： $\quad 1.45495 e 4 \quad 2390.64086$ 


\section{Compound 18b}

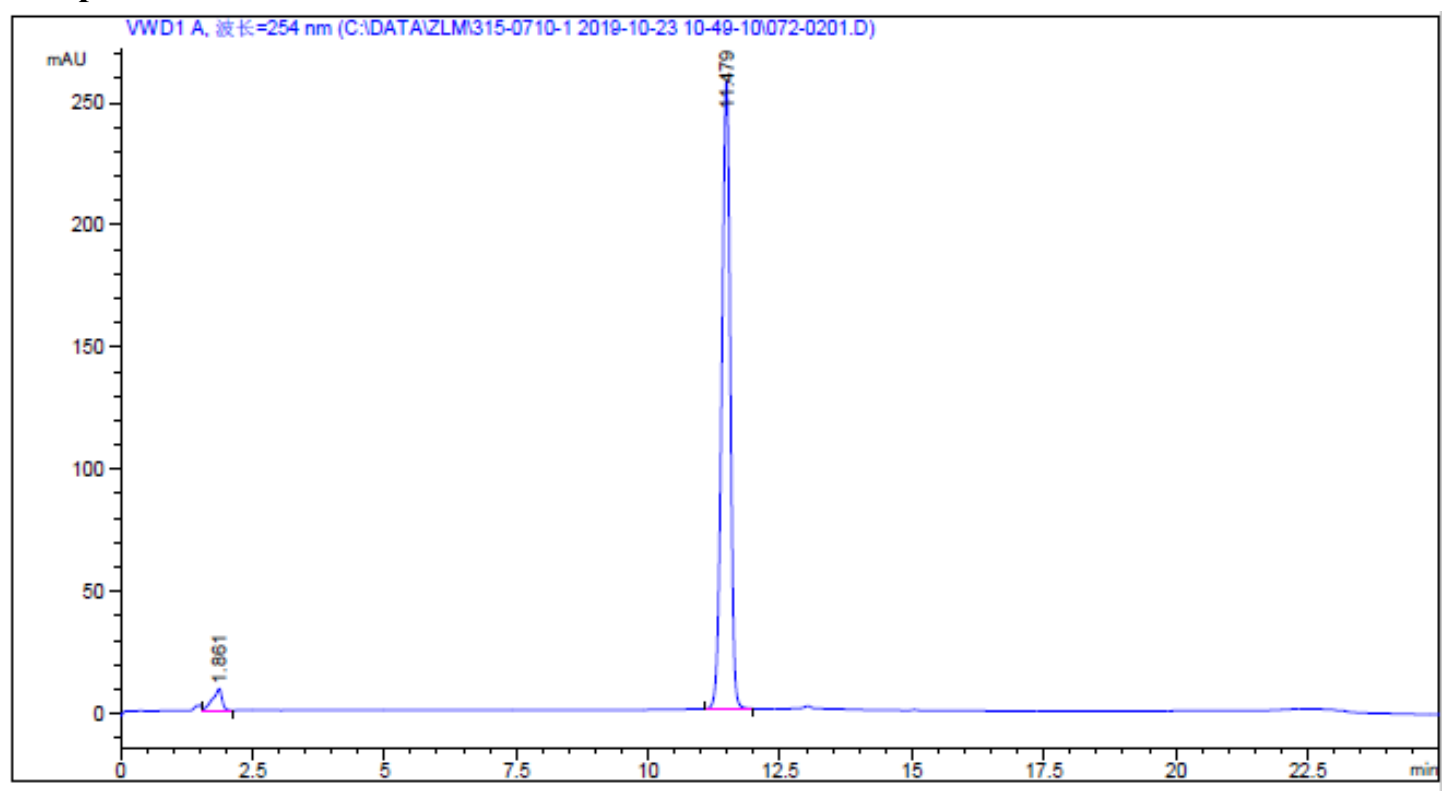

面积百分比报告

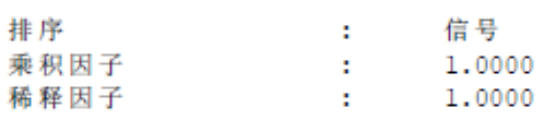

内标使用乘积因子和稀释因子

信号 1: VWD1 A, 波长 $=254 \mathrm{~nm}$

峰保留时间类型峰赛峰面积峰高峰面积

$\begin{array}{ccccccc}\text { \# }[\mathrm{min}] & {[\mathrm{min}]} & \mathrm{mAU} & { }^{*} 3 & {[\mathrm{mAU}]} & \text { \% } \\ 1 & 1.861 \text { VV } & 0.1700 & 111.12978 & 8.92902 & 3.7166\end{array}$

$\begin{array}{lrlllll}2 & 11.479 & \text { BB } & 0.1757 & 2878.99341 & 257.20532 & 96.2834\end{array}$

总量： $\quad 2990.12319 \quad 266.13434$ 


\section{Compound 18d}

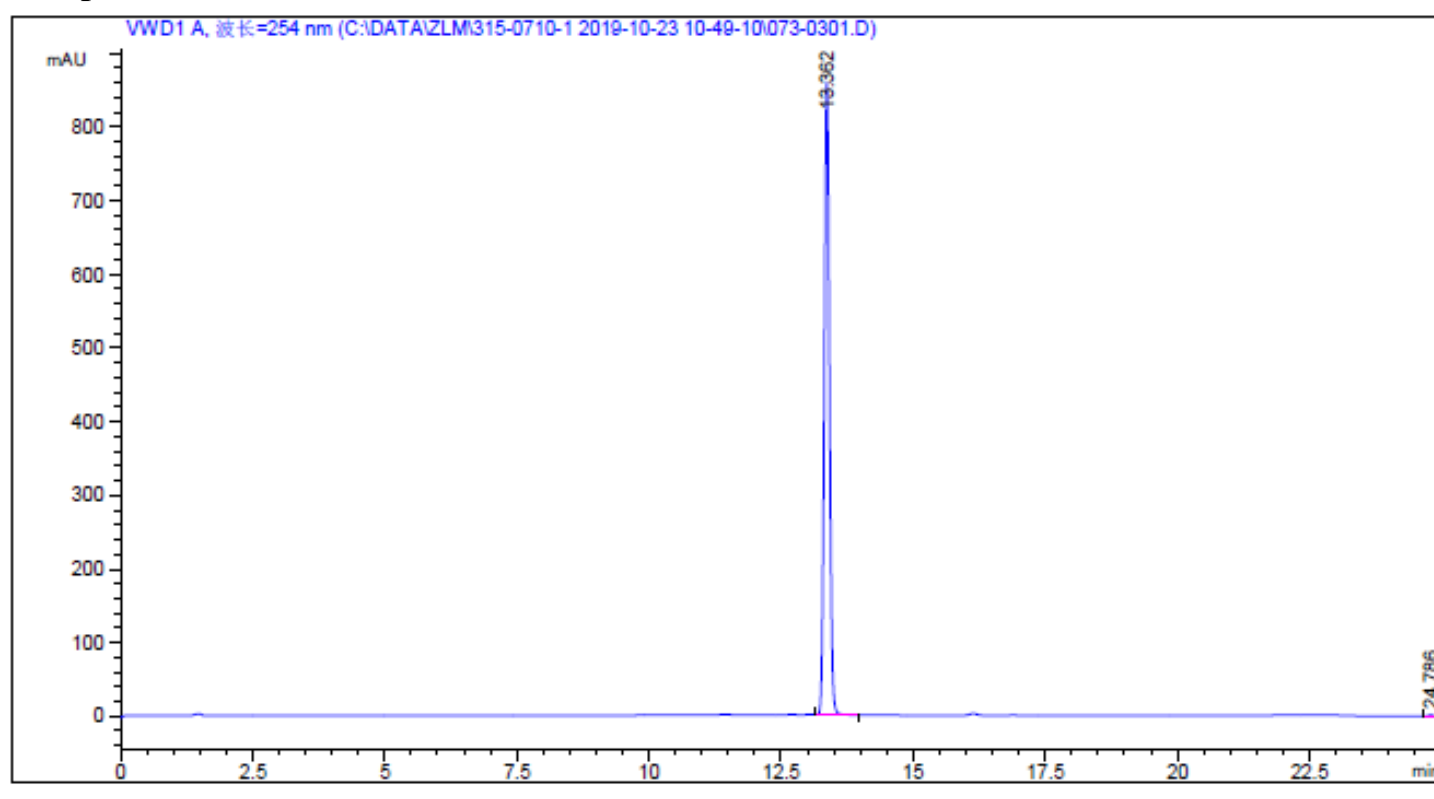

面积百分比报告

$\begin{array}{lll}\text { 排序 } & : & \text { 信号 } \\ \text { 乘积因子 } & : & 1.0000 \\ \text { 稀释因子 } & : & 1.0000\end{array}$

内标使用乘积因子和稀释因子

信号 1: VWD1 A, 波长 $=254 \mathrm{~nm}$

\begin{tabular}{|c|c|c|c|c|c|c|}
\hline 峰 & 保留时间 & 类型 & 峰䆓 & 峰面积 & 峰高 & 峰面积 \\
\hline$\neq$ & [min] & & {$[\mathrm{min}]$} & $\mathrm{MAU} \times \mathrm{*}$ & {$[\mathrm{mAU}$} & 옹 \\
\hline & ------ & & ------- & |--------- & 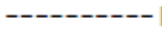 & $--\cdots--$ \\
\hline 1 & 13.362 & VB & 0.1073 & 5870.75879 & 860.09473 & 99.7923 \\
\hline 2 & 24.786 & $\mathrm{VBA}$ & 0.0985 & 12.21722 & 1.93272 & 0.2077 \\
\hline 总量 & : & & & 5882.9 & 862.02745 & \\
\hline
\end{tabular}




\section{Compound 18e}

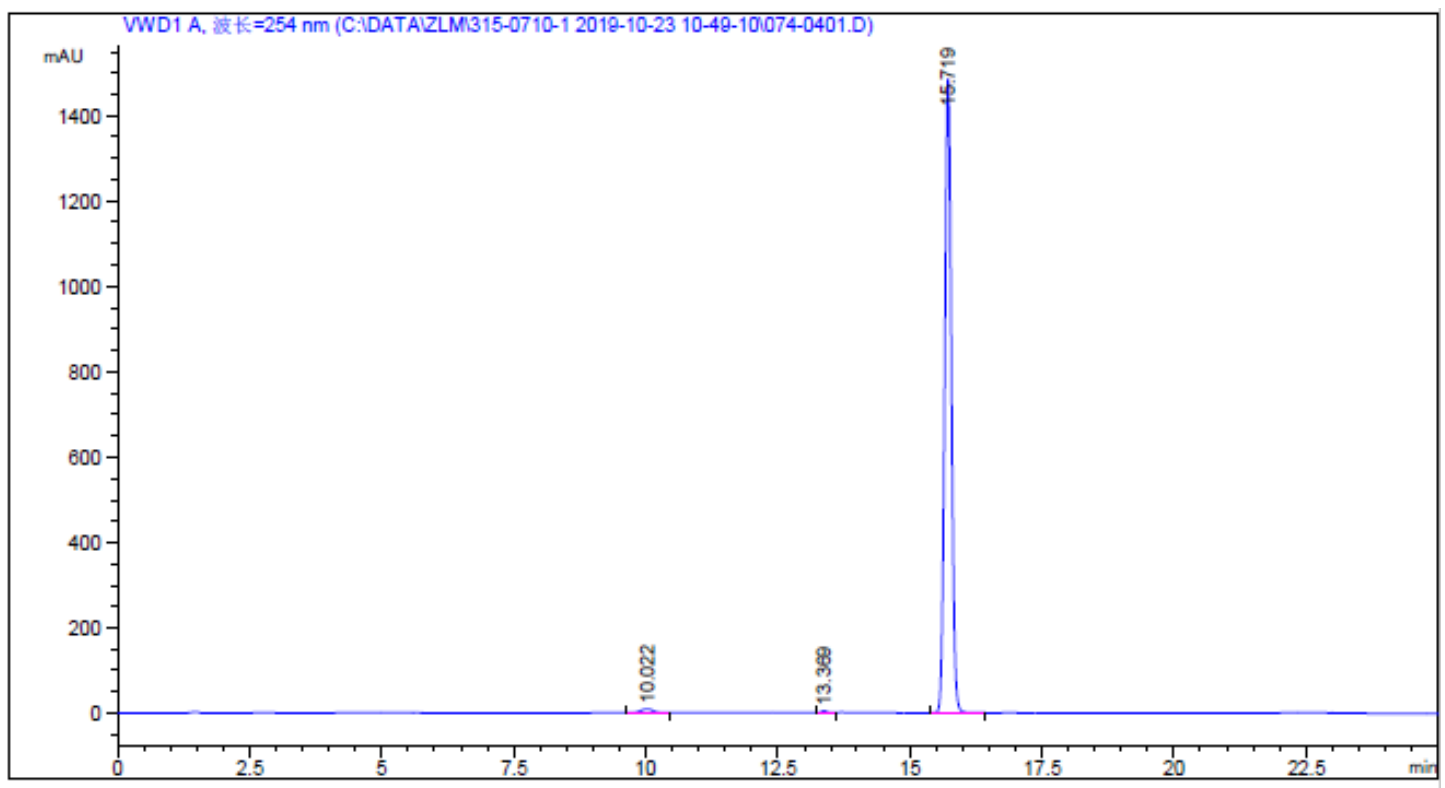

面积百分比报告

排序

乘积因子

稀释因子

信号

内标使用乘积因子和稀释因子

信号 1: VWD1 A, 波长 $=254 \mathrm{~nm}$

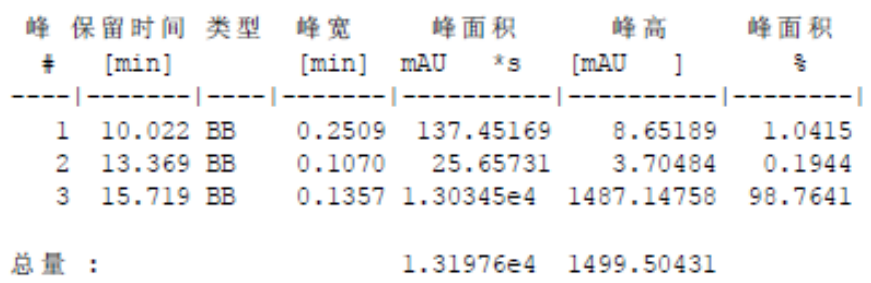




\section{Compound 18g}

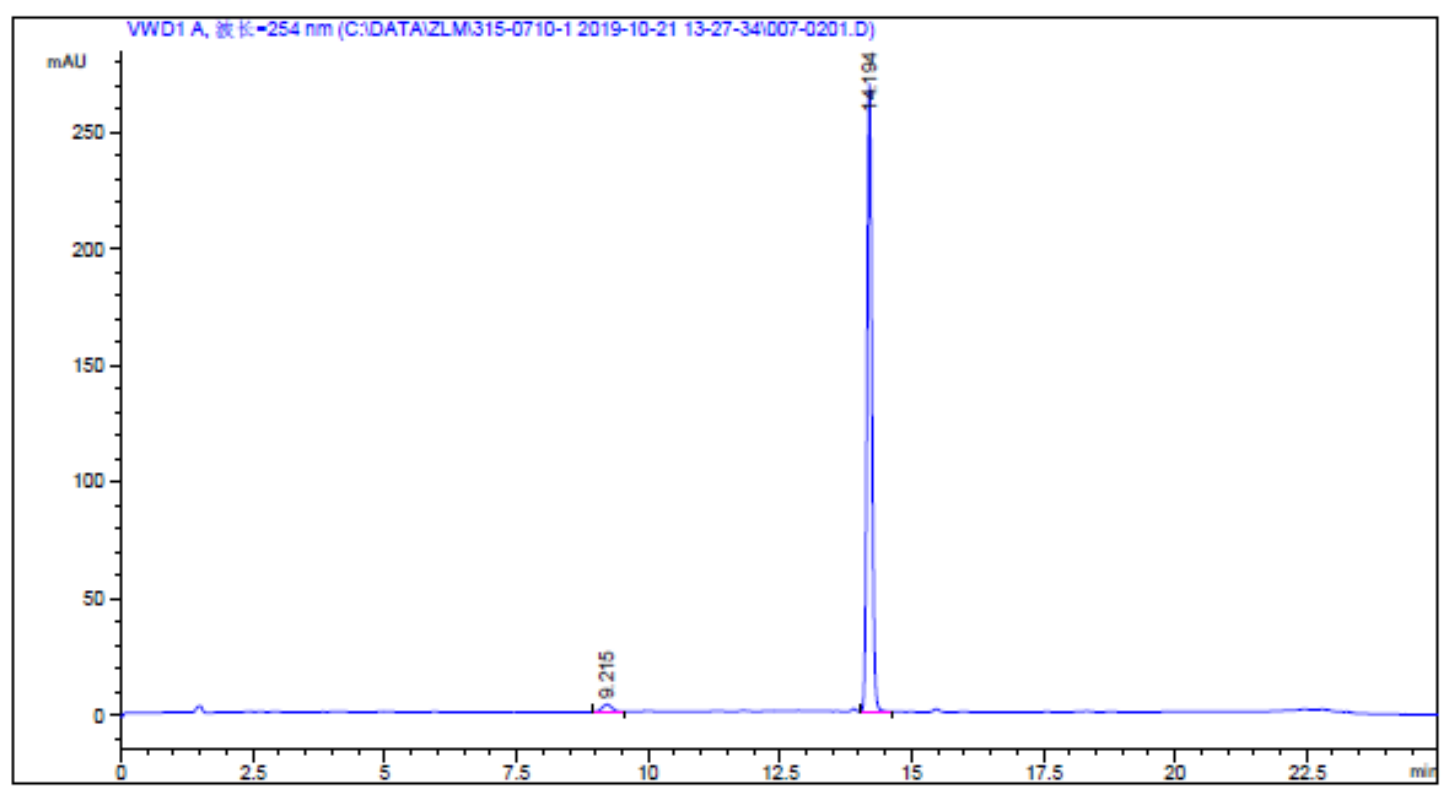

面积百分比报告

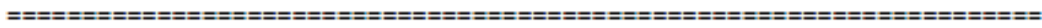

推序

乘积因子

都蜘因子

内标使用乘积因子和新释因子

信号 1: VWD1 A, 波长 $=254 \mathrm{~nm}$

\begin{tabular}{|c|c|c|c|c|c|c|c|c|}
\hline 峰 & 保留时间 & 类型 & 峰宽 & & 百积 & 峰 & & 峰面积 \\
\hline$\#$ & {$[\min ]$} & & [min] & $\mathrm{mAU}$ & $* 5$ & ImAD & ] & \& \\
\hline 1 & 9.215 & $\mathrm{BB}$ & 0.1977 & & 95037 & & 4430 & 2.2717 \\
\hline 2 & 14.194 & VB & 0.0977 & 1718 & 68469 & 269. & 54767 & 97.7283 \\
\hline 急量 & - & & & 175 & 63506 & 272. & 79197 & \\
\hline
\end{tabular}




\section{Compound 19a}

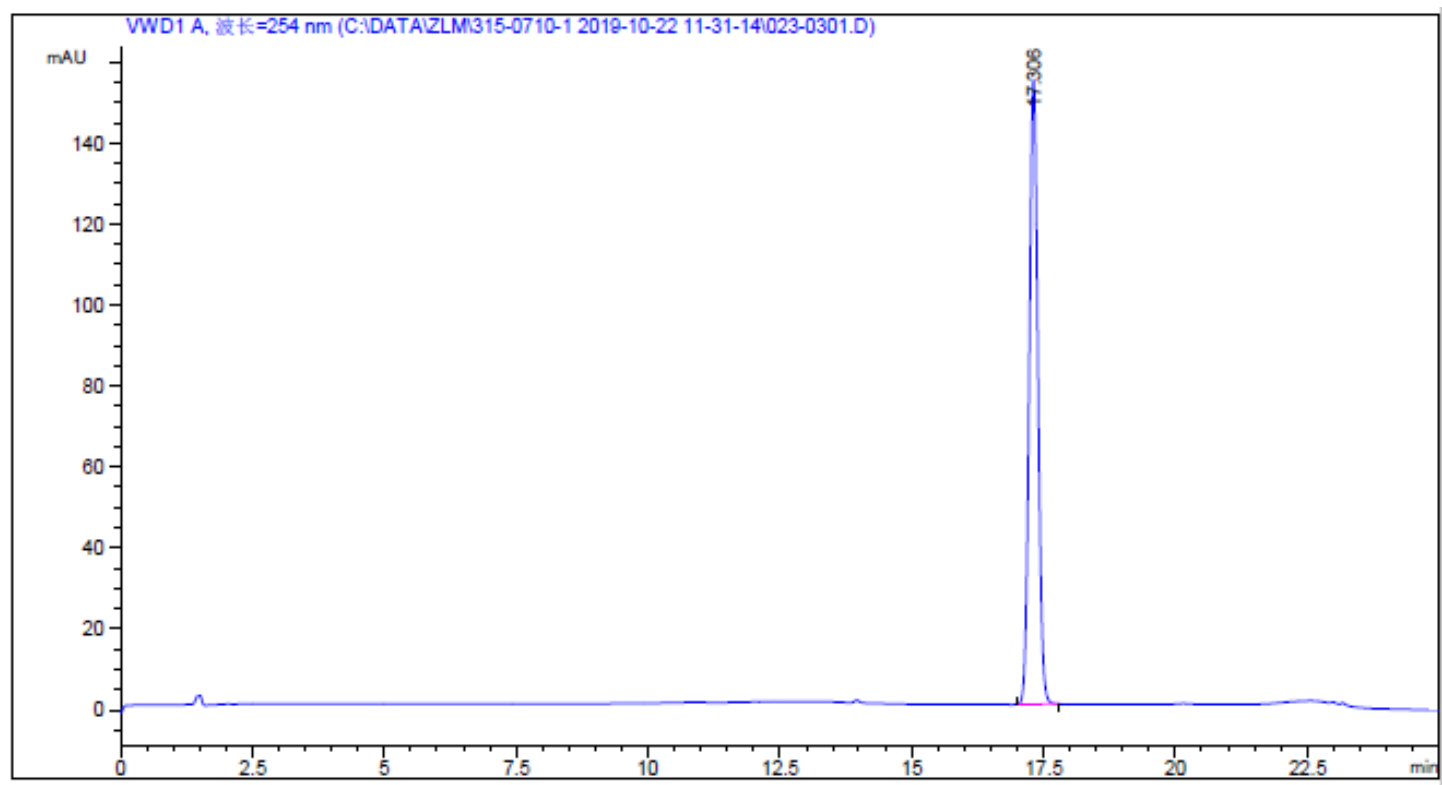

\section{面积百分比报告}

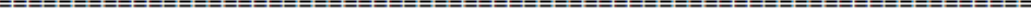

$\begin{array}{lll}\text { 排序 } & : & \text { 信号 } \\ \text { 乘积因子 } & : & 1.0000 \\ \text { 稀秚因子 } & : & 1.0000\end{array}$

内标使用乘积因子和稀释因子

信号 1: VWD1 A, 波长 $=254 \mathrm{~nm}$

峰保留时间类型峰宽峰面积峰高峰面积

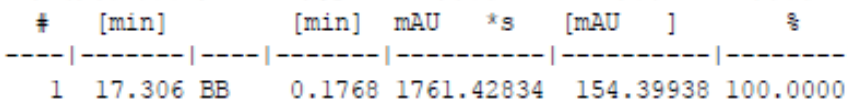

总量： $1761.42834 \quad 154.39938$ 


\section{Compound 19b}

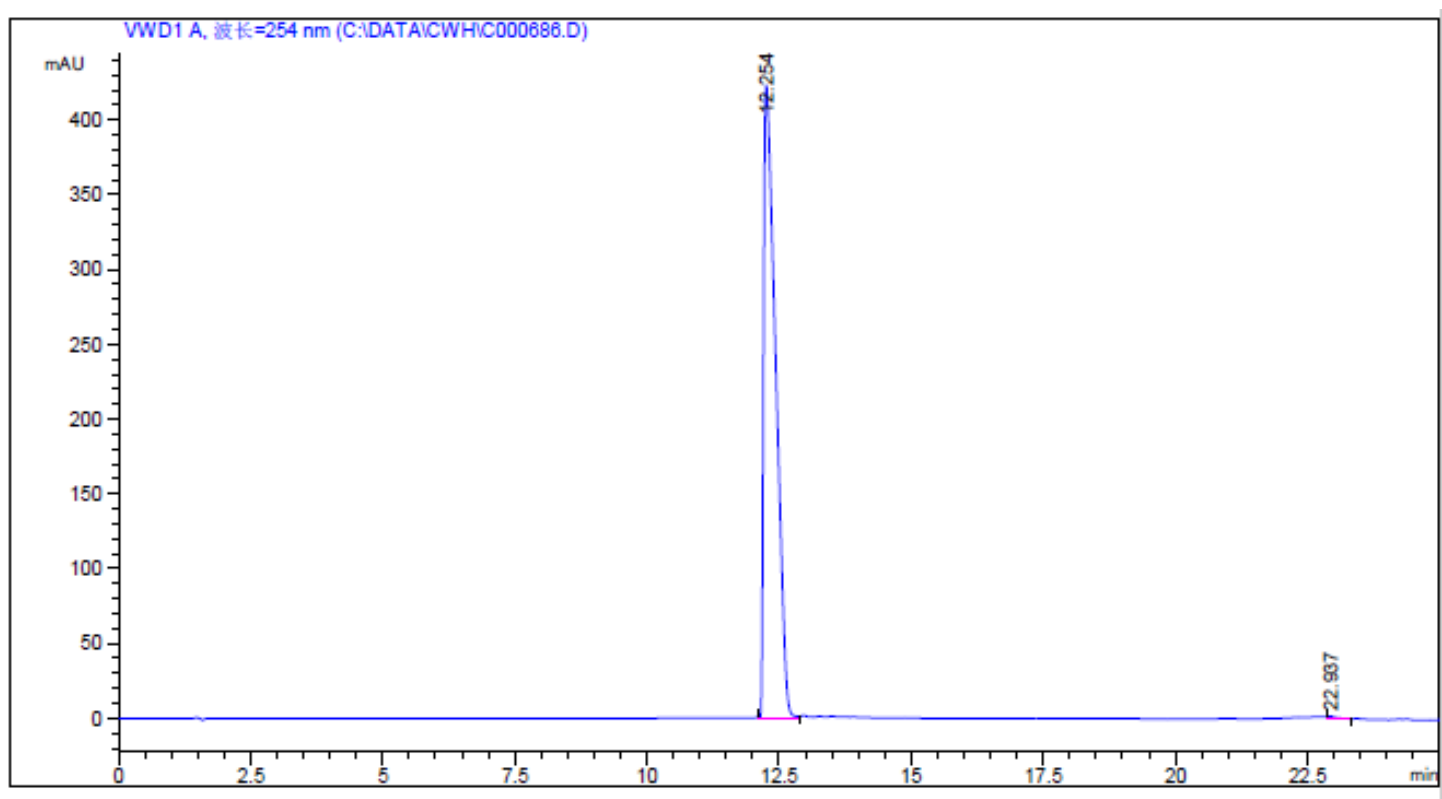

面积百分比报告

$\begin{array}{lll}\text { 排序 } & : & \text { 信号 } \\ \text { 乘积因子 } & : & 1.0000 \\ \text { 稀释因子 } & : & 1.0000\end{array}$

内标使用乘积因子和稀释因子

信号 1: VWD1 A, 波长 $=254 \mathrm{~nm}$

\begin{tabular}{|c|c|c|c|c|c|c|}
\hline 峰 & 保留时间 & 类型 & 峰寨 & 峰面积 & 峰高 & 峰面积 \\
\hline$\#$ & [min] & & [min] & MAU ${ }^{*} s$ & {$\left[\begin{array}{ll}\mathrm{mAU} & ]\end{array}\right.$} & 8ำ \\
\hline-- & 等 & & --- & |----o-d & --.-- & $--\infty-\infty$ \\
\hline 1 & 12.254 & VV & 0.2550 & 6658.84229 & 422.99832 & 99.5305 \\
\hline 2 & 22.937 & VV & 0.1954 & 31.40786 & 2.09390 & 0.4695 \\
\hline 总量 & : & & & 6690.25015 & 425.09222 & \\
\hline
\end{tabular}




\section{Compound 19c}

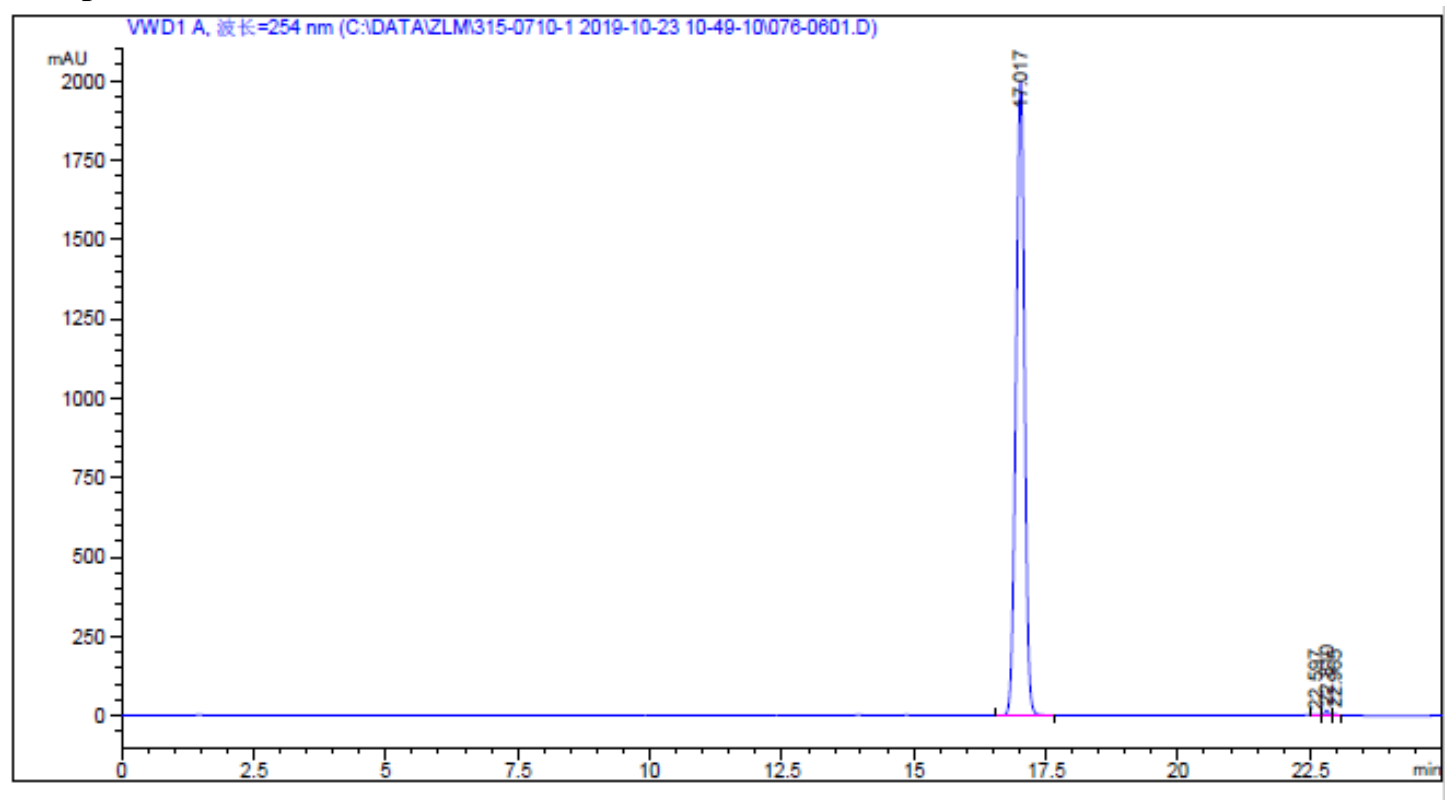

面积百分比报告

$\begin{array}{lll}\text { 排序 } & : & \text { 信号 } \\ \text { 乘积因子 } & : & 1.0000 \\ \text { 稀释因子 } & : & 1.0000\end{array}$

内标使用乘积因子和稀释因子

信号 1: VWD1 A, 波长 $=254 \mathrm{~nm}$

\begin{tabular}{|c|c|c|c|c|c|c|}
\hline 峰 & 保留时间 & 类型 & 峰宽 & 峰面积 & 峰高 & 峰面积 \\
\hline \# & [min] & & [min] & $\mathrm{mAU} \times \mathrm{*}$ & {$[\mathrm{mAU}$} & 옹 \\
\hline & & & $-\cdots$ & - & - & 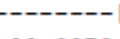 \\
\hline 1 & 17.017 & VB & 0.1752 & $2.25509 e 4$ & 1999.76782 & 99.3 \\
\hline 2 & 597 & VV & 0.1245 & 26.62042 & 3.02638 & .73 \\
\hline 3 & 22.810 & VV & 0.0771 & 82.62545 & 16.17526 & 0.3642 \\
\hline 4 & 22.965 & VV & 0.0853 & 27.51684 & 4.63664 & 0.1213 \\
\hline
\end{tabular}

总量： $\quad 2.26876 \mathrm{e} 4 \quad 2023.60610$ 


\section{Compound 19d}

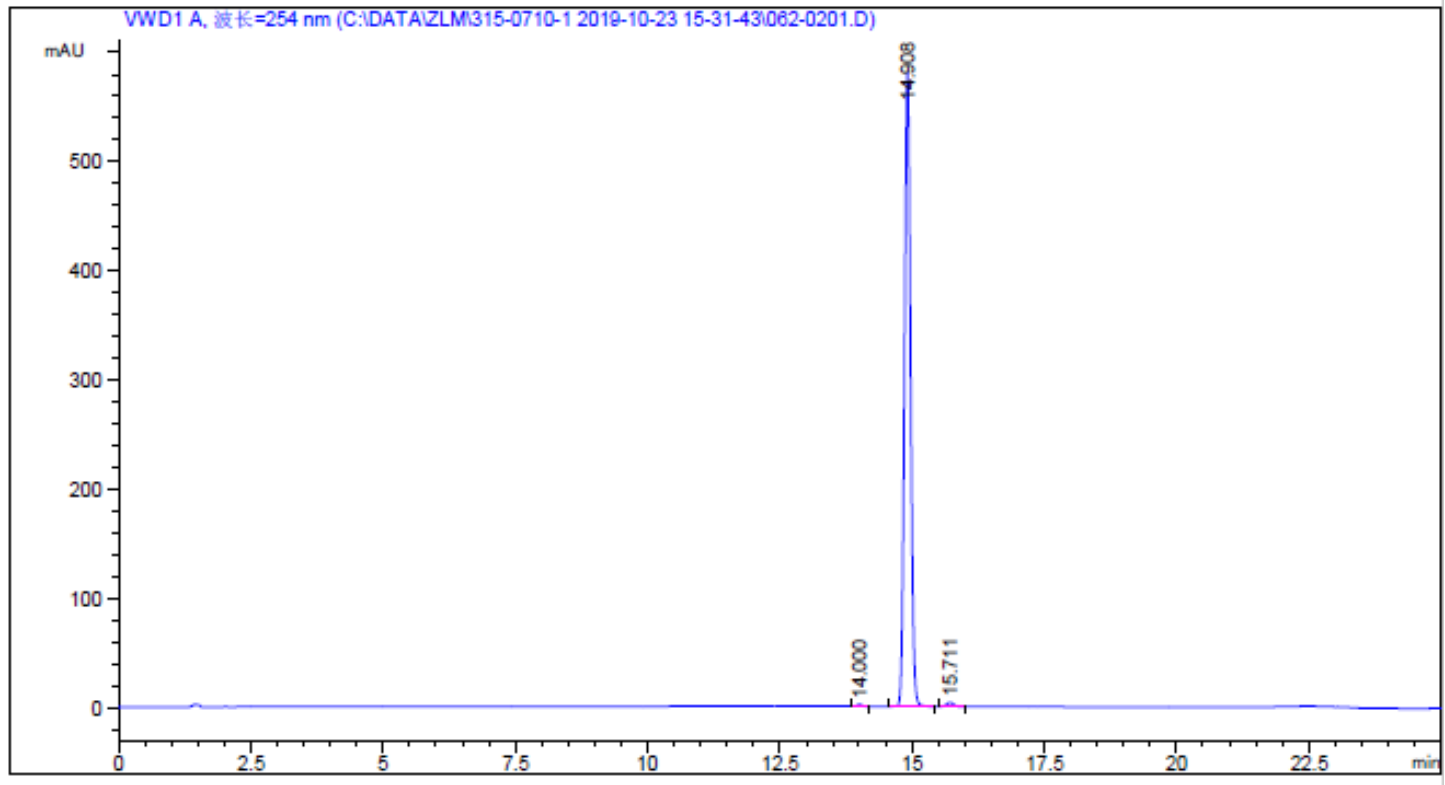

面积百分比报告

排序

乘积因子

稀释因子

信号

内标使用乘积因子和稀释因一

信号 1: VWD1 A, 波长 $=254 \mathrm{~nm}$

\begin{tabular}{|c|c|c|c|c|c|c|}
\hline 蜂 & 保留时间 & 类型 & 峰宽 & 峰面积 & 峰高 & 峰面积 \\
\hline \# & [min] & & {$[\mathrm{min}]$} & mAU & {$[\mathrm{mAd}$} & 웅 \\
\hline 1 & & & 060 & 12.23 & 78883 & \\
\hline 2 & 14.9 & $B B$ & 0.1238 & 4638.48193 & 580.25482 & 98.9 \\
\hline 3 & 15.711 & $\mathrm{BB}$ & 0.1497 & 36.38663 & 3.74783 & 0.7763 \\
\hline
\end{tabular}

总量： $4687.10024 \quad 585.79149$ 


\section{Compound 19e}

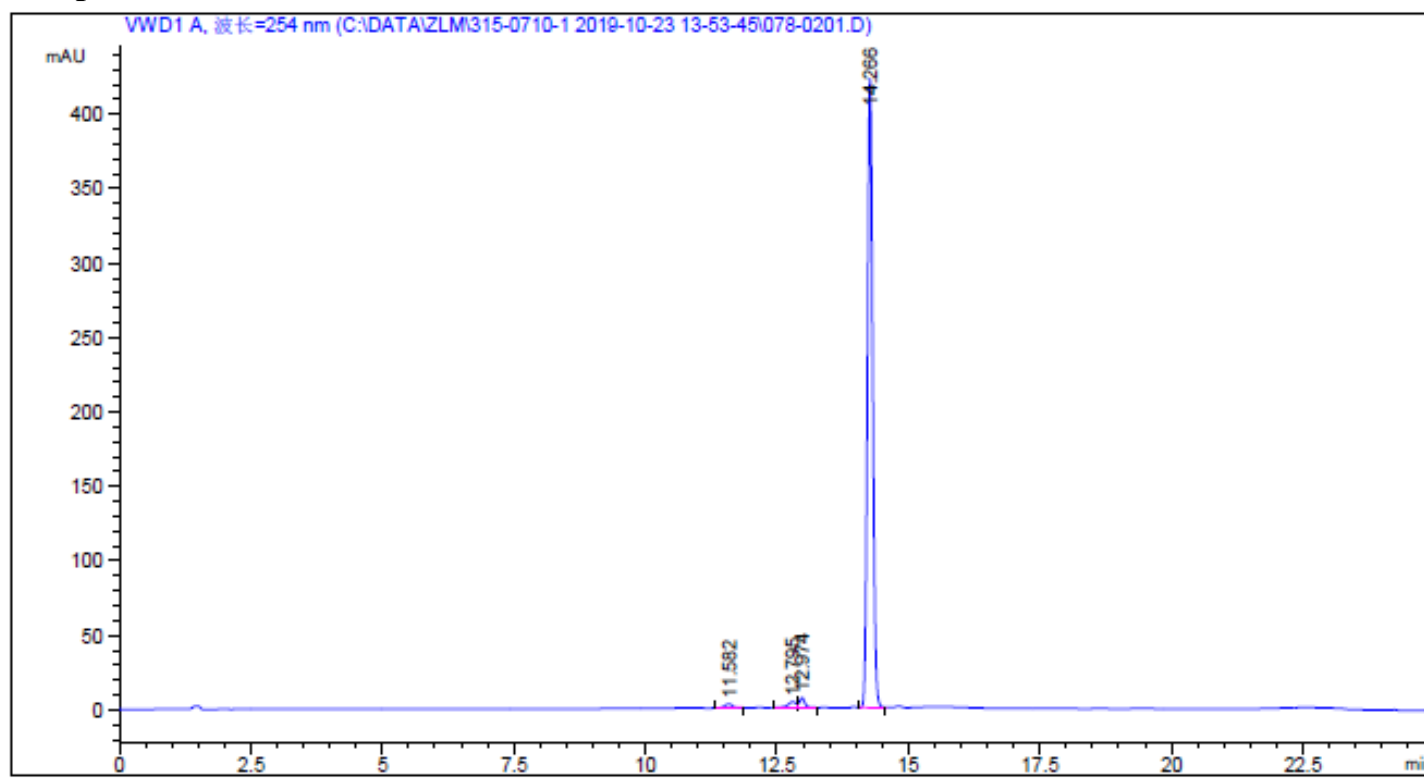

\section{面积百分比报告}

\section{排序}

信号

乘积因子

稀秚因子

: 1.0000

内标使用乘积因子和程释因子

信号 1: VWD1 A, 波长 $=254 \mathrm{~nm}$

\begin{tabular}{|c|c|c|c|c|c|c|}
\hline 峰 & 保留时间 & 类型 & 峰赛 & 峰面积 & 峰高 & 峰面积 \\
\hline \# & [min] & & {$[\mathrm{min}]$} & $\mathrm{mAU} \quad * 3$ & {$[\mathrm{mAd}$} & 웅 \\
\hline 1 & 11.582 & $B B$ & 0.1642 & 28.28488 & 2.67317 & 0.9249 \\
\hline 2 & 12.795 & BV & 0.1625 & 45.67379 & 4.08331 & 1.4935 \\
\hline 3 & 12.974 & VB & 0.1116 & 51.17461 & 6.76171 & 1.6733 \\
\hline 4 & 14.266 & VV & 0.1070 & 2933.10864 & 423.37830 & 95.9083 \\
\hline 总量 & . & & & 3058.24192 & 436.89649 & \\
\hline
\end{tabular}




\section{Compound 19f}

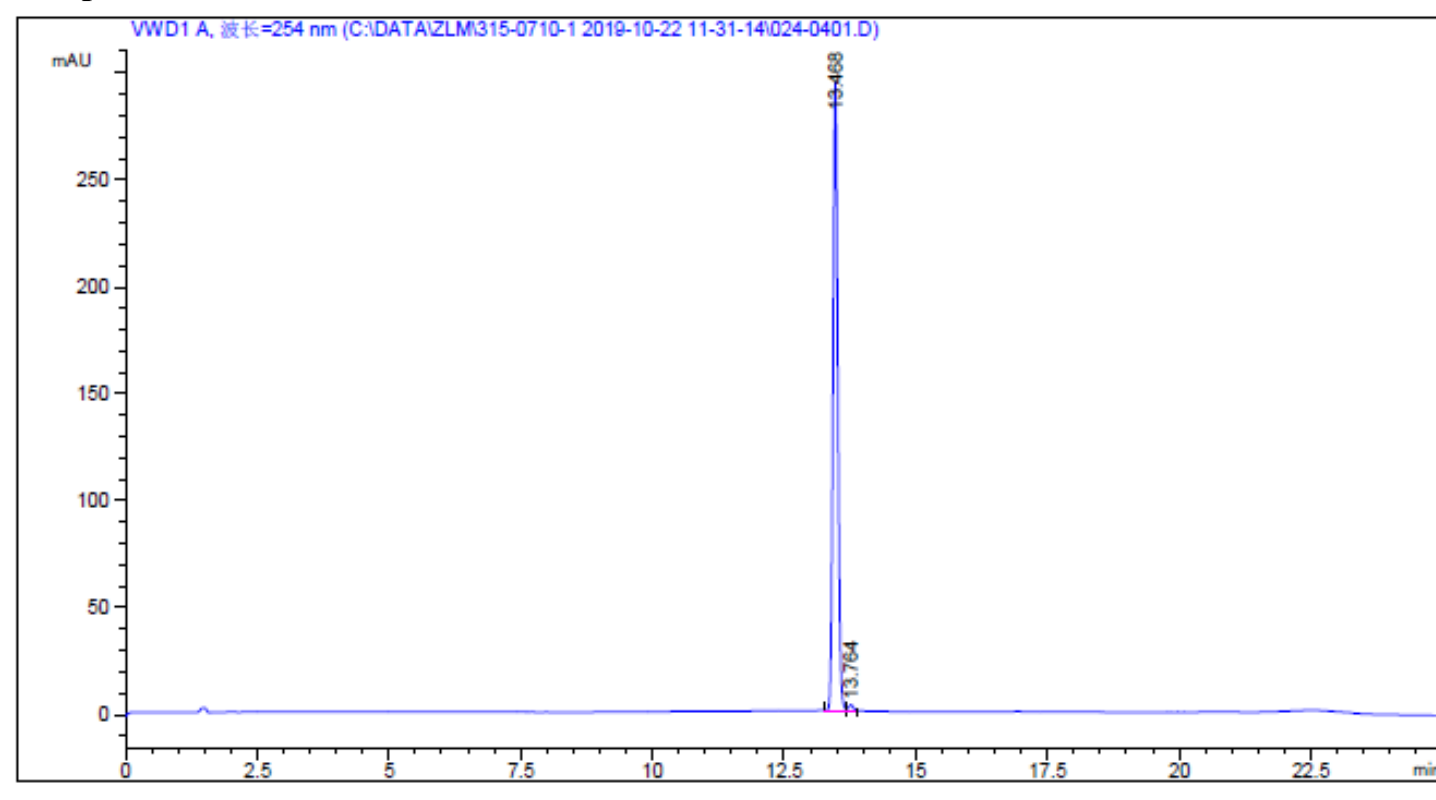

面积百分比报告

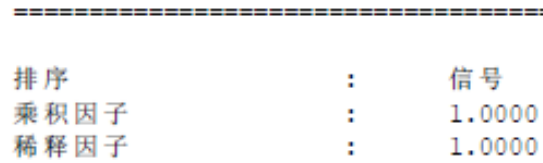

内标使用乘积因子和稀释因子

信号 1: VWD1 A, 波长 $=254 \mathrm{~nm}$

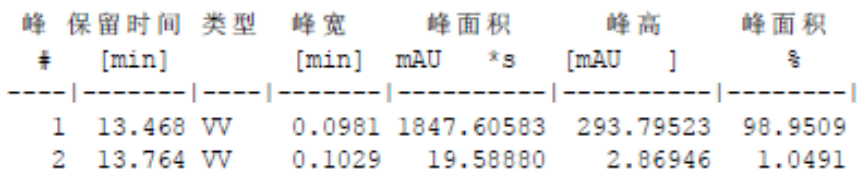

总量 :

$1867.19464 \quad 296.66469$ 


\section{Compound 19g}

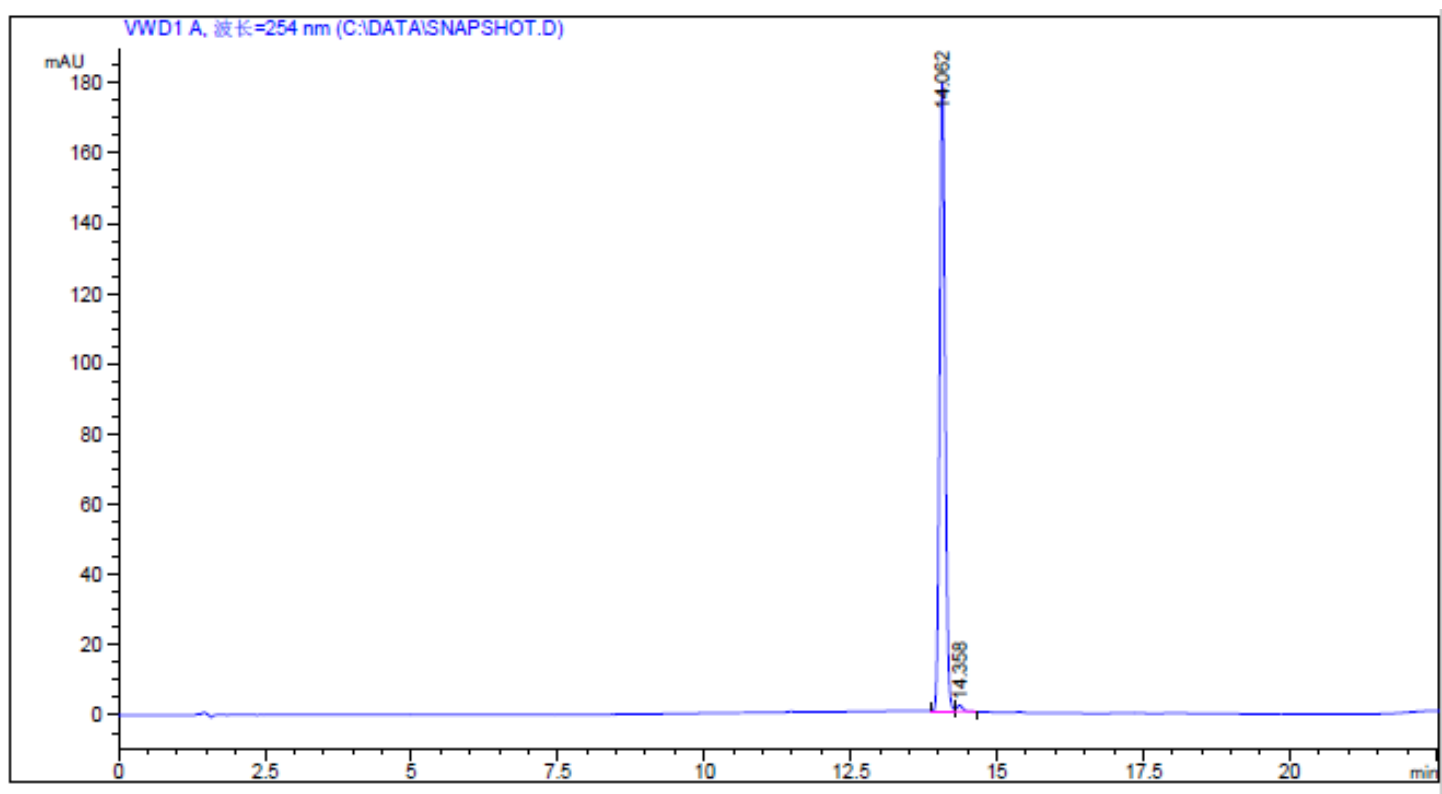

面积百分比报告

$\begin{array}{lll}\text { 排序 } & : & \text { 信号 } \\ \text { 乘积因子 } & : & 1.0000 \\ \text { 稀释因子 } & : & 1.0000\end{array}$

内标使用乘积因子和稀释因子

信号 1: VWD1 A, 波长 $=254 \mathrm{~nm}$

\begin{tabular}{|c|c|c|c|c|c|c|}
\hline 峰 & 保留时间 & 类型 & 峰赛 & 峰面积 & 峰离 & 峰面积 \\
\hline$\neq$ & [min] & & [min] & $\mathrm{mAU} \quad{ }^{*} \mathrm{~s}$ & {$[\mathrm{mAU}$} & 옹 \\
\hline 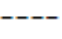 & ---- & & ------ & 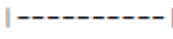 & 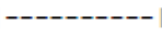 & ------ \\
\hline 1 & 14.062 & VV & 0.1027 & 1176.39160 & 179.41223 & 98.8540 \\
\hline 2 & 14.358 & VB & 0.1150 & 13.63803 & 1.76336 & 1.1460 \\
\hline 量 & : & & & 1190.02963 & 181.17559 & \\
\hline
\end{tabular}




\section{Compound 19h}

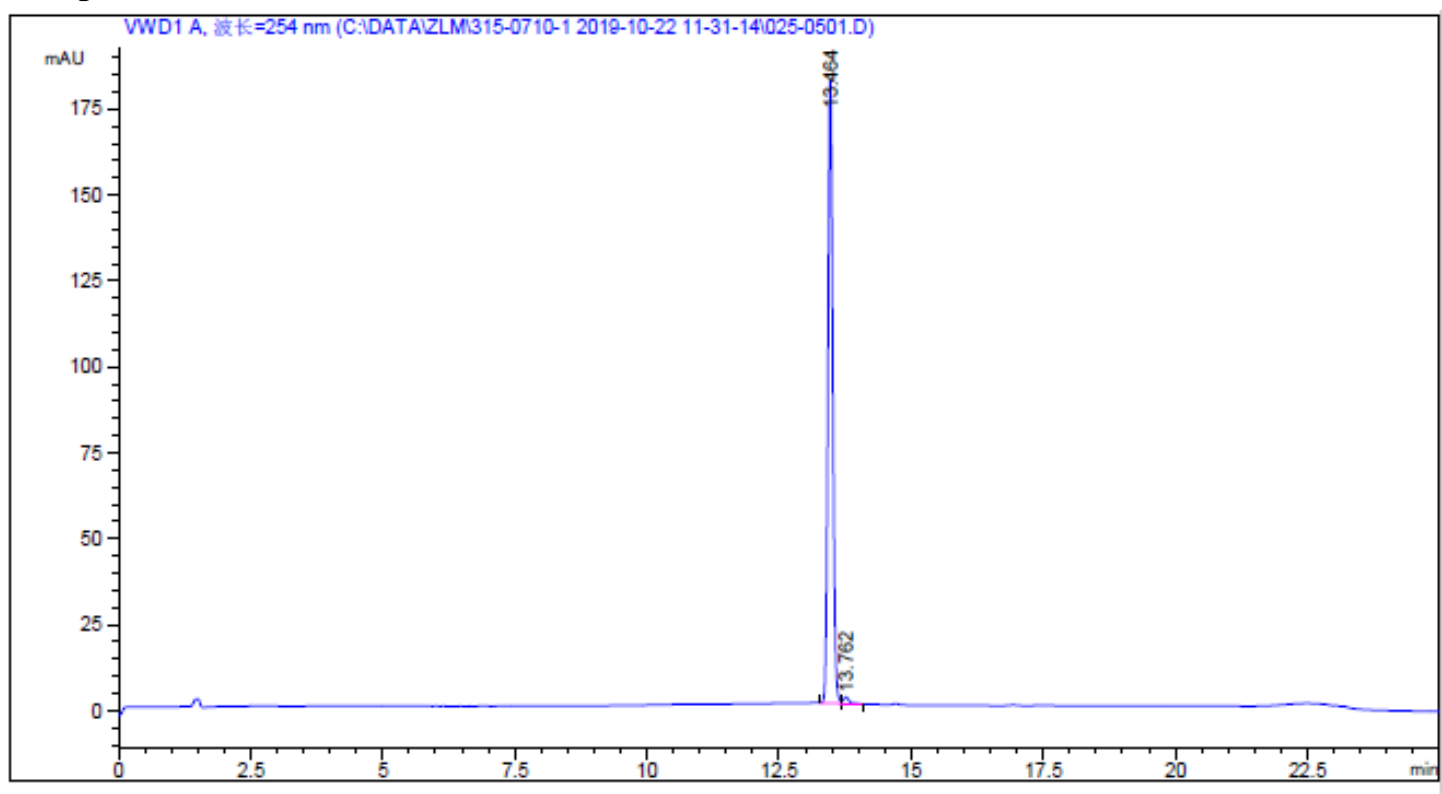

面积百分比报告

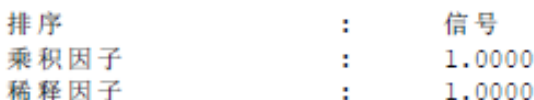

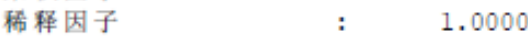

内标使用乘积因子和稀释因子

信号 1: VWD1 A, 波长 $=254 \mathrm{~nm}$

峰保留时间类型峰宽峰面积峰高峰面积

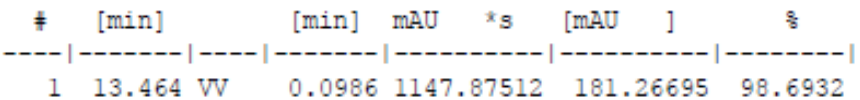

$\begin{array}{lrrrrr}1 & 13.464 \mathrm{VV} & 0.0986 & 1147.87512 & 181.26695 & 98.6932 \\ 2 & 13.762 \mathrm{VB} & 0.1147 & 15.19951 & 1.97063 & 1.3068\end{array}$

总量： $1163.07464 \quad 183.23758$ 


\section{Reference}

1. Alen, J.; Smets, W. J.; Dobrzańska, L.; De Borggraeve, W. M.; Compernolle, F.; Hoornaert, G. J., Diastereoselective Diels-Alder additions of ethene to substituted homochiral 2(1H)-pyrazinones. Eur. J. Med. Chem. 2007, (6), 965-971.

2. Van der Eycken, E.; Appukkuttan, P.; Husain, M.; Gupta, R.; Parmar, V., A chemoselective microwave-assisted one-pot cross-stille reaction of benzylic halides with 2(1H)-pyrazinones using simultaneous cooling. Synlett. 2006, (10), 1491-1496. 